\title{
Scaling Relations of Local Magnitude versus Moment Magnitude for Sequences of Similar Earthquakes in Switzerland
}

\author{
by Falko Bethmann, Nicholas Deichmann, and P. Martin Mai
}

\begin{abstract}
Theoretical considerations and empirical regressions show that, in the magnitude range between 3 and 5, local magnitude, $M_{\mathrm{L}}$, and moment magnitude, $M_{\mathrm{w}}$, scale 1:1. Previous studies suggest that for smaller magnitudes this $1: 1$ scaling breaks down. However, the scatter between $M_{\mathrm{L}}$ and $M_{\mathrm{w}}$ at small magnitudes is usually large and the resulting scaling relations are therefore uncertain. In an attempt to reduce these uncertainties, we first analyze the $M_{\mathrm{L}}$ versus $M_{\mathrm{w}}$ relation based on 195 events, induced by the stimulation of a geothermal reservoir below the city of Basel, Switzerland. Values of $M_{\mathrm{L}}$ range from 0.7 to 3.4. From these data we derive a scaling of $M_{\mathrm{L}} \sim 1.5 M_{\mathrm{w}}$ over the given magnitude range. We then compare peak Wood-Anderson amplitudes to the low-frequency plateau of the displacement spectra for six sequences of similar earthquakes in Switzerland in the range of $0.5 \leq M_{\mathrm{L}} \leq 4.1$. Because effects due to the radiation pattern and to the propagation path between source and receiver are nearly identical at a particular station for all events in a given sequence, the scatter in the data is substantially reduced. Again we obtain a scaling equivalent to $M_{\mathrm{L}} \sim 1.5 M_{\mathrm{w}}$. Based on simulations using synthetic source time functions for different magnitudes and $Q$ values estimated from spectral ratios between downhole and surface recordings, we conclude that the observed scaling can be explained by attenuation and scattering along the path. Other effects that could explain the observed magnitude scaling, such as a possible systematic increase of stress drop or rupture velocity with moment magnitude, are masked by attenuation along the path.
\end{abstract}

\section{Introduction}

Conversions of magnitude scales for small earthquakes play an important role for hazard calculations in low to moderate seismicity areas such as Switzerland. They are also important for magnitude recurrence calculations to estimate the seismicity decay to background level following reservoir stimulation in geothermal energy production. However, the range of events that determines a potential hazard in the latter case is orders of magnitude lower than in earthquake hazard calculations.

The first magnitude that is usually available after an earthquake is local magnitude $\left(M_{\mathrm{L}}\right)$ because of its fast and standardized determination procedures. However, due to its limitations (e.g., saturation toward high magnitudes) the more physically based moment magnitude $\left(M_{\mathrm{w}}\right)$ is the preferred magnitude scale today. In principle, assuming that local and moment magnitude are measures of the size of an earthquake, a general agreement is expected over a wide range of magnitudes. In practice, however, empirically derived relations show a different behavior. The relation of $M_{\mathrm{L}}$ versus $M_{\mathrm{w}}$ is better characterized by $M_{\mathrm{L}} \sim m M_{\mathrm{w}}$, with the value of $m$ being close to 1.5 for small $\left(M_{\mathrm{L}} \leq 3.5\right)$ events and $m=1$ for larger magnitudes. A first review of moment-magnitude relations over a wide range of magnitudes was published by Hanks and Boore (1984) for earthquakes in central and southern California. They found a nonlinear relation that can be approximated by two lines, having a proportionality factor $m$ of 1.25 for earthquakes of $1.5 \leq M_{\mathrm{L}} \leq 3.5$ and $m=$ 1 for earthquakes of $3 \leq M_{\mathrm{L}} \leq 6$ (Bakun, 1984). Grünthal and Wahlström (2003) compared magnitudes based on data from 25 local catalogs and 30 studies of earthquakes in central, northern, and northwestern Europe. They derive a second order polynomial to obtain an improved fit for magnitudes in the range of $-0.8 \leq M_{\mathrm{L}} \leq 6.2$ with the vast majority of events being $M_{\mathrm{L}}>1.5$. The catalog was later extended in magnitude range and time period by Grünthal et al. (2009). Alternative relations of $\log \left(M_{0}\right)$ or $M_{\mathrm{w}}$ versus $M_{\mathrm{L}}$ have been determined in several studies (see Hanks and Boore [1984], Grünthal et al. [2009], and Deichmann [2006] for a compilation). In the relations of $M_{\mathrm{L}} \sim m M_{\mathrm{w}}$, the scale factor $m$ varies between 0.97 and 2.25 , depending on magnitude range, geographical region, and algorithm for the calculation of $M_{\mathrm{w}}$. Moreover, an attempt to define a global relationship 
failed due to varying magnification of different WoodAnderson (WA) instruments (Scordilis, 2006) and different calibration of local magnitude scales.

A working group at the Swiss Seismological Service made an effort to calibrate various magnitude scales to $M_{\mathrm{w}}$ (Braunmiller et al., 2005). Moment magnitude thus became the basis for the Earthquake Catalog of Switzerland (ECOS) and is henceforth used for updating the seismic hazard map of Switzerland. The linear regression between $M_{\mathrm{L}}$ and $M_{\mathrm{w}}$ in the range of $2.7 \leq M_{\mathrm{L}} \leq 4.9$ had a proportionality factor close to 1 ; therefore, the conversion between $M_{\mathrm{L}}$ and $M_{\mathrm{w}}$ was defined by subtracting a constant offset of 0.2 from $M_{\mathrm{L}}$. A deviation from a linear relationship for magnitudes $M<2$, however, was observed by Morasca et al. (2005) from a comparison of $M_{\mathrm{L}}$ and coda derived $M_{\mathrm{w}}$ in the western Alps. Such a deviation would have consequences for magnitude recurrence relations ( $b$ values) and thus influences seismic hazard calculations (e.g., short-term forecasts). Additionally, systematic deviations of $M_{\mathrm{L}}$ relative to $M_{\mathrm{w}}$ might be indicative of variations in stress drop or rupture velocity, if effects of wave propagation and instrument response are properly corrected for and radiation pattern effects and rupture directivity are averaged out (Deichmann, 2006).

In general, with decreasing magnitude, values for the scale factor $m$ increase as a result of the passband that is formed by the attenuation along the path and the instrument response (Boore, 1989). For the determination of $M_{\mathrm{L}}$ for small earthquakes, the corner frequency will be above the high pass of the WA-instrument, and $m$ will be affected by the low pass of attenuation only. However, source effects such as an increase of stress drop or rupture velocity with moment can also lead to increased $m$ values. Also, for events below magnitude 2 the comparison between $M_{\mathrm{L}}$ and $M_{\mathrm{w}}$ usually results in a wider scatter of magnitudes compared with events in a higher magnitude range, thus rendering the determination of $m$ more difficult. The scatter is caused by few available recordings and inaccurate or missing focalmechanism information. High-quality data recorded at close distances and preferably events with similar focal mechanism and wave-propagation path are therefore required to examine earthquake scaling for magnitudes $M<2$. If an earthquake's focal mechanism is known, it can be used to eliminate radiation pattern effects on single-station estimates of seismic moment. Furthermore, for events with almost identical waveforms one can assume similar focal mechanisms, facilitating a scaling analysis at lower magnitudes even if the radiation characteristics are unknown. Similar earthquakes, occurring as natural event sequences or hydrofractureinduced seismicity due to reservoir stimulation in regions of geothermal production provide exactly such data.

In this work, we benefit from being able to exploit both types of data, including a unique dataset of induced seismicity, recorded in the city of Basel (Switzerland) due to water injection for a geothermal power plant, allowing us to study in detail the relation of $M_{\mathrm{L}}$ versus $M_{\mathrm{w}}$ for small magnitudes.

In our study, we use high-resolution broadband recordings for magnitude determination, augmented with nearby borehole stations as well as strong-motion data. We first compare local against moment magnitude for a series of induced earthquakes for which fault planes and radiation characteristics are well constrained. We then eliminate uncertainties in source and path by focusing on sequences of

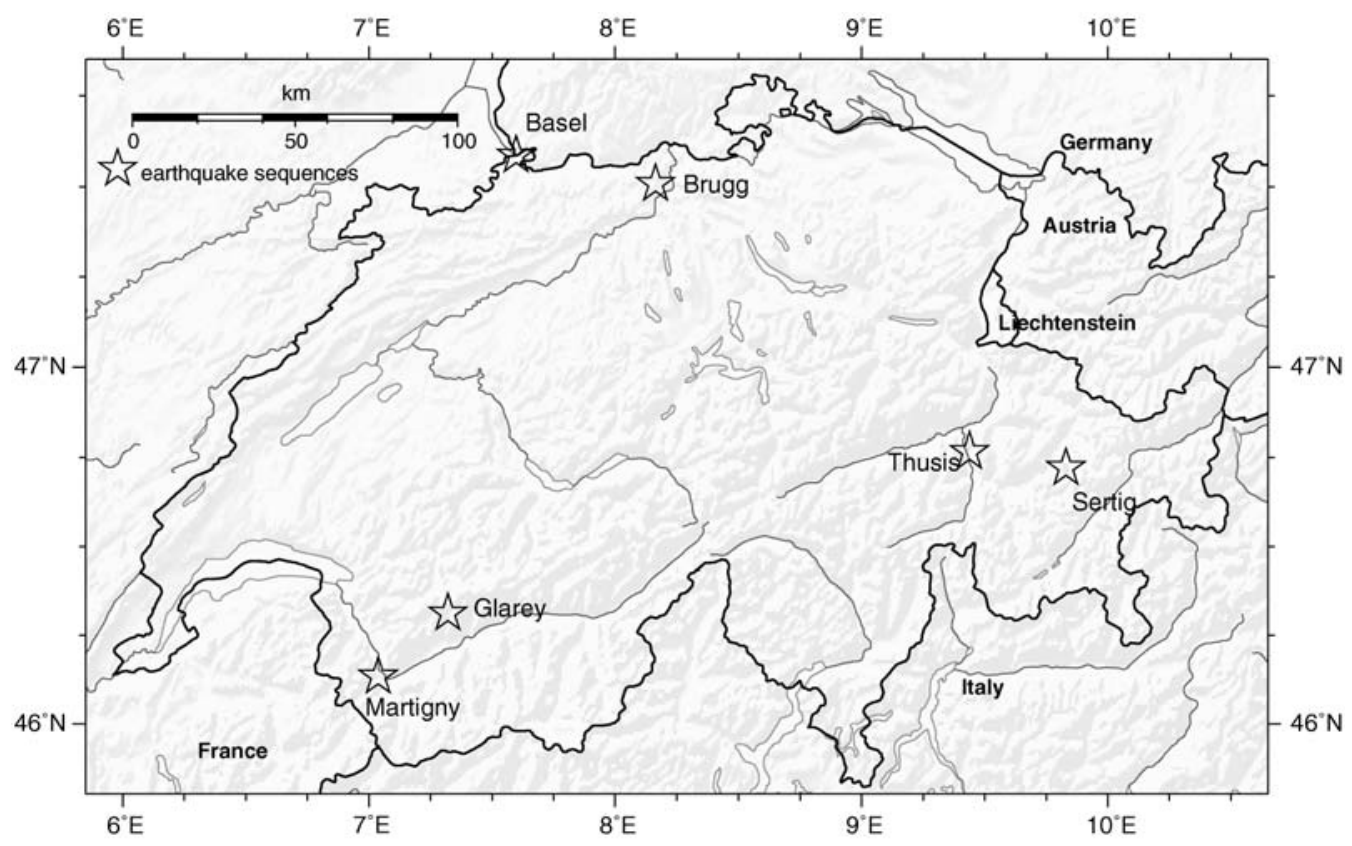

Figure 1. Map of Switzerland with the earthquake sequences used for this study. Although the earthquakes in Basel were induced by water injection, the other sequences are of natural origin and occurred from 2001 to 2009. The datasets are described in detail in the Appendix. 
similar earthquakes that occurred from 2001 to 2009 in Switzerland (Fig. 1). To quantify the effect of anelastic attenuation compared with effects of varying source parameters on magnitude scaling, we also compare our results to theoretical models of wave propagation in anelastic media using a source model of Sato (1994).

\section{$M_{\mathrm{L}}$ versus $M_{\mathrm{w}}$ for the Induced Seismicity of Basel}

\section{The Induced Earthquakes in Basel}

For the scaling analysis of $M_{\mathrm{L}}$ versus $M_{\mathrm{w}}$, we use data obtained during fluid injection for a pilot project for geothermal energy exploitation (deep heat mining) in the city of Basel (Häring et al., 2008). The strongest induced earthquake had a local magnitude of 3.4 and was widely felt in the city of Basel, reaching macroseismic intensities of IV to V (EMS-98). The dataset analyzed in this section consists of the 195 events with $M_{\mathrm{L}}$ between 0.7 and 3.4 recorded by the national network of the Swiss Seismological Service. Focal mechanisms could be determined for 49 events. The dataset is well suited to determine $M_{\mathrm{L}}$ and $M_{\mathrm{w}}$ because the events occurred in a rather small source volume of $0.6 \mathrm{~km}^{3}$ (Deichmann and Giardini, 2009), and the data were recorded by a dense network of stations. A more detailed description of the induced earthquakes within the city of Basel can be found in the Appendix.

\section{Local Magnitude}

Local magnitude is calculated following standard procedures of the Swiss Seismological Service (SED). Signals are digitally filtered to emulate the response of a Wood-Anderson seismograph; $M_{\mathrm{L}}$ is then determined from the maximum zero-to-peak amplitude of the resulting horizontal seismograms. Attenuation with epicentral distance is accounted for by an empirically derived attenuation relation (Kradolfer and Mayer-Rosa, 1984). No further station corrections are applied. The event magnitude is equal to the median of all individual station magnitudes. A detailed description of $M_{\mathrm{L}}$ estimation at the SED can be found in Braunmiller et al. (2005). Variations in magnitude estimates at each station occur due to the azimuthal dependence of the seismic energy emitted at the source and the local station properties (location, site characteristics). The median over a sufficient number of stations usually provides stable estimates of magnitude. In the case of the induced events in Basel, 157 out of 195 magnitudes were determined from amplitude recordings of four or more broadband stations of the Swiss Digital Seismic Network. Thirty-eight magnitudes of $M_{\mathrm{L}} 1.6$ or lower were determined from two or three amplitude recordings.

\section{Moment Magnitude}

Moment magnitude is used at the Swiss Seismological Service in the new earthquake catalog (ECOS2009) and as a basis for the seismic hazard map of Switzerland. For recent earthquakes above magnitude $3.5, M_{\mathrm{w}}$ is derived from moment tensors (Clinton et al., 2006), based on long-period waveform recordings. For the induced events in Basel, however, this technique of determining $M_{\mathrm{w}}$ via moment tensors is not applicable. Instead we derive moment magnitude from the seismic moment $M_{0}$ (in $\mathrm{Nm}$ ) using the relation of Hanks and Kanamori (1979):

$$
M_{\mathrm{w}}=\frac{2}{3} \log M_{0}-6.03 .
$$

The seismic moment is calculated using the modified ray theoretical representation for the displacement of a heterogeneous elastic medium (Aki and Richards, 2002, chap. 4, equation 93 and the following). We approximate the geometrical spreading with $1 /$ distance, which is justified by the short hypocentral distances in our dataset, and add the variable $S$ to account for reflected arrivals. After integration over time, we obtain

$$
M_{0}=\frac{4 \pi \rho_{\xi}^{\frac{1}{2}} \rho_{x}^{\frac{1}{2}} v_{\xi}^{\frac{5}{2}} v_{x}^{\frac{1}{2}}}{F_{\theta \Phi} S} R_{\xi x} \Omega_{0} .
$$

Equation (2) includes station and location specific information such as density and velocity at the source $\left(\rho_{\xi}, v_{\xi}\right)$ and the receiver $\left(\rho_{x}, v_{x}\right)$, radiation coefficient $\left(F_{\theta \Phi}\right)$ that depends on azimuth $(\Phi)$ and takeoff angle $(\theta)$, amplification at free surface $(S)$, hypocentral distance $\left(R_{\xi x}\right)$, and $\Omega_{0}$ the lowfrequency amplitude of the far-field displacement spectrum $\left(P_{g^{-}}, S_{g}\right.$-phase), or equivalently the displacement pulse area.

Velocity and density information at the source is obtained from borehole logs. Near-surface velocity and density information at the station sites in Basel and surrounding areas are taken from ambient vibration array measurements (Havenith et al., 2007). For stations at greater distance for which no borehole logs or ambient array measurements are available, a 3D velocity model of Diehl et al. (2009) is used. The receiver velocities $\left(\rho_{x}, v_{x}\right)$ are estimated by a quarterwavelength approximation as proposed by Joyner et al. (1981). Hypocentral distance $\left(R_{\xi x}\right)$ is taken from master event locations (Deichmann and Giardini, 2009). For the present study, fault-plane solutions are available for 49 events ( 28 of these are documented in Deichmann and Ernst, 2009). For these events, radiation coefficients $\left(F_{\theta \Phi}\right)$ were calculated directly from the respective focal mechanisms. Given that 41 of the 49 events have strike-slip mechanisms, we approximated the radiation coefficients of the events with unknown mechanisms by using average values of the radiation coefficients of these strike-slip events. This assumption leads to less scatter between moment-magnitude estimates at each station compared with mean radiation coefficients of Aki and Richards (2002). The free surface amplification factors $(S)$ were calculated from the incidence angles of the ray at each station derived from $2 \mathrm{D}$ raytracing. For most of the stations, which are located at short epicentral distances, the angles of incidence are nearly vertical. Thus, the resulting 
amplification factor for $P$ waves is 1.95 . For $S$ waves the wavefront arrives at the station at a near vertical incidence angle; hence, it is justified to restrict the analysis to the $S_{H}$ wave, for which the surface amplification factor is 2 (Aki and Richards, 2002).

Following the procedure of Abercrombie (1995), we determine $\Omega_{0}$ by fitting the observed spectrum with a synthetic spectrum

$$
\Omega(f)=\frac{\Omega_{0} e^{-(\pi f t / Q)}}{\left[1+\left(f / f_{c}\right)^{\gamma n}\right]^{1 / \gamma}} .
$$

Equation (3) represents the amplitude of the far-field displacement spectrum as a function of frequency $f$. The spectrum is composed of a source term and an exponential path term. The source term is parameterized by the corner frequency $f_{c}$ and the exponents $n$ and $\gamma$. The exponent $n$ is the high frequency fall-off rate on a log-log plot and $\gamma$ is a constant with a value of 1 or 2 , depending on the spectral model used for fitting. A $\gamma$ of 1 corresponds to the source spectrum originally derived by Brune (1970). A $\gamma$ of 2 is a modification by Boatwright (1980), which produces a sharper corner at the high frequency cutoff. The exponential term describes the amplitude decay due to anelastic attenuation and scattering; the decay rate depends on the travel time $t$ and the quality factor $Q$.

For fitting the observed spectrum with the theoretical one, we use a grid search for the unknown parameters $\Omega_{0}$, $f_{c}$, and exponent $n$. For $\gamma$ we chose a value of 1 , which leads to a better fit compared to a value of 2 . We limit our search parameters to $\frac{1}{2} \Omega_{p} \leq \Omega_{0} \leq 2 \Omega_{p}, \Omega_{p}$ being the area under the single-sided displacement pulse, $\frac{1}{2} \frac{1}{\Pi} \leq f_{c} \leq 3 \frac{1}{\Pi}$, , being the pulse width and $1 \leq n \leq 4$.

(a)

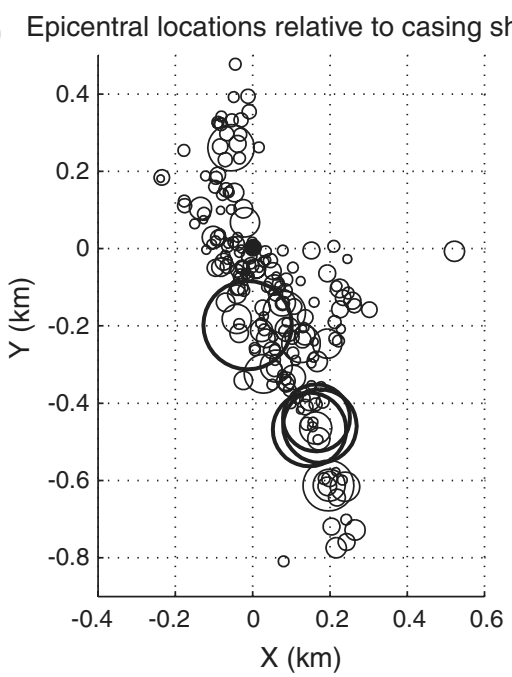

A detailed description of our procedure for estimating $Q$ is given in the section Comparison with Theoretical Model. For the Basel sequence, we determine $Q$ values between the source volume and surface stations in the range $30 \leq Q \leq 50$. For borehole stations we calculate depthdependent $Q$ values between 56 and 800 . However, because we are interested in the $\Omega$ value at low frequencies, the exact value of $Q$ is of little interest here, as a variation in $Q$ particularly affects the high-frequency spectral decay but leaves values at lower frequencies unchanged.

\section{Data Processing}

Seismic data for the Basel geothermal project were acquired by three separate institutions. Borehole sensors of Geothermal Explores Ltd. were placed at depths of $2740 \mathrm{~m}$ (OTER2), $1213 \mathrm{~m}$ (RIEH2), $553 \mathrm{~m}$ (MATTE), $542 \mathrm{~m}$ (HALTI), $500 \mathrm{~m}$ (OTER1), and at $317 \mathrm{~m}$ (JOHAN). The Landeserdbebendienst Baden-Württemberg (Germany) provided data recorded at 18 high-gain seismometers and 11 accelerometers. The Swiss Seismological Service (SED) recorded events on 40 high-gain seismometers and 23 accelerometers. To date, the SED detected 195 events in the immediate vicinity of the borehole site with $M_{\mathrm{L}}$ ranging between 0.7 and 3.4 (Fig. 2).

To obtain displacement seismograms, strong-motion data are first demeaned and integrated to velocity. Together with broadband and borehole velocity data, seismograms are then rotated into the direction of maximum energy using the method of Jackson et al. (1991). It provides estimates of signal and noise energy and the degree of rectilinearity of polarization (Esmersoy, 1984). We used the maximum

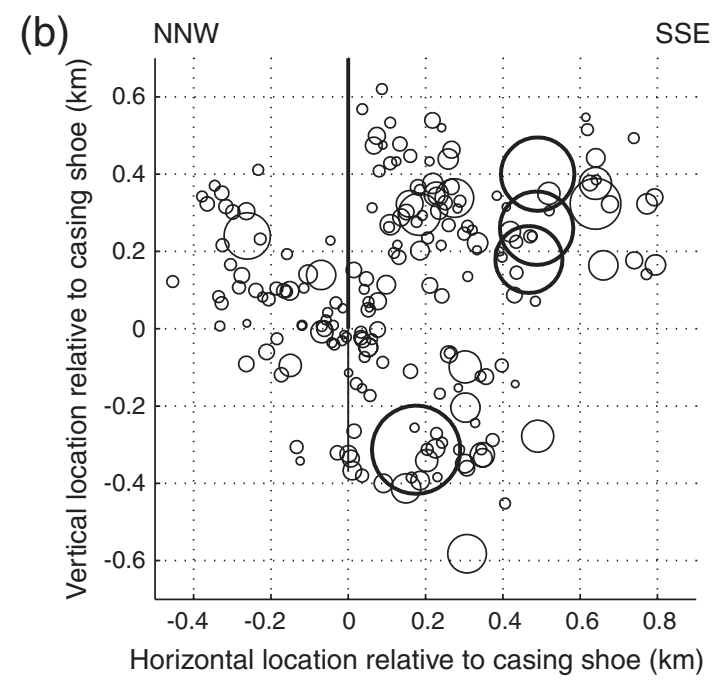

Figure 2. Master event relocations of the 195 strongest events induced by water injection below the city of Basel between December 2006 and November 2007 (Deichmann and Giardini, 2009). (a) An epicenter plot of the borehole is shown; (b) a depth cross-section of the master event locations perpendicular to the general trend of the epicenter alignment. The coordinates in both plots are relative to the casing shoe (beginning of the open-hole section). In (a) the well is marked by the black dot $(0,0)$; in (b) the cased section of the well is marked by the thick line and the open-hole section by the thin line. The size of each circle is proportional to the seismic moment of the event. The largest circle at a depth of $-0.3 \mathrm{~km}$ represents the $M_{\mathrm{L}} 3.4$ mainshock of 8 December 2006. 
energy component because the orientation of the borehole sensors is unknown. Tests comparing the described method of Jackson et al. (1991) matched results using a method that rotates into a ray-oriented coordinate system. However, due to certain deficiencies (e.g., sensitivity to noise and sensor orientation), the latter method could not be automated. In the case of borehole stations and for the $P$ wave, we use all three velocity components for rotation; in the case of the $S$ wave, where the wave encounters the surface sensor at an almost vertical angle, we use horizontal components only ( $S_{H}$ phase). We manually select time windows for rotation as described in the following paragraph. Results are compared with rotations using longer time intervals. In the case of nonmatching waveforms, the recording is discarded. The final displacement seismogram is obtained by demeaning and integrating the maximum energy component.

In this study we are particularly interested in single unipolar pulses, which we detect and select in a manual picking procedure. The underlying assumption is that all contributions of the source are contained in a single pulse leaving at a specific takeoff angle $(\theta)$ to the station. Information following the first main pulse is assumed not to contribute to seismic moment (area under the curve averages out) or belongs to other phases and not to the direct arrival. This assumption fails for events with complex rupture history, or for seismograms with low signal-to-noise ratio. However, those cases are avoided by manually selecting only those signals with unipolar shaped pulses of $P$ or $S$ phases. For further processing we remove the offset of the first sample of the displacement pulse and remove the trend of the seismogram if present. The procedure is demonstrated in Figure 3. The resulting seismogram will start and end with

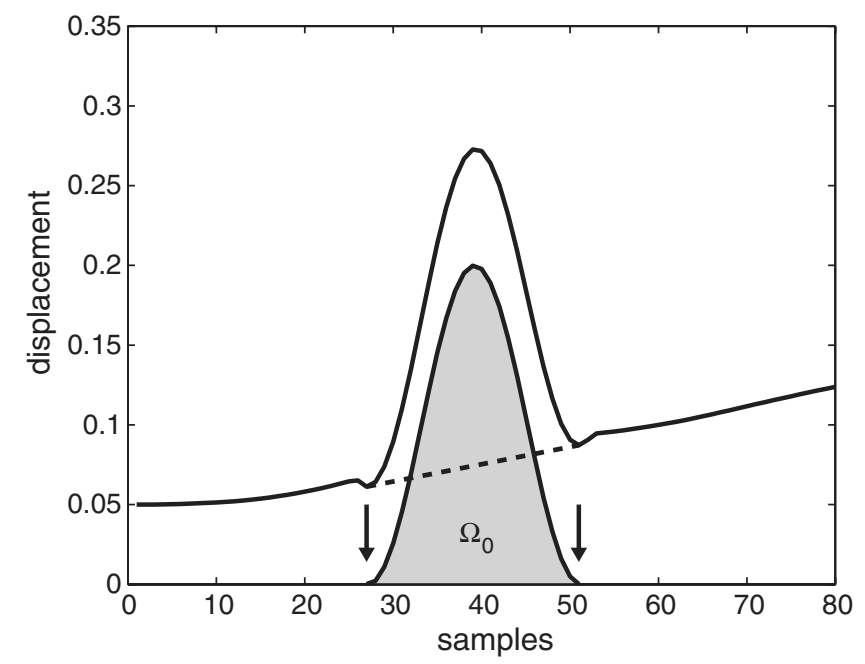

Figure 3. Example of manual processing of the unipolar displacement pulse (including low level noise). We manually pick beginning and end of the pulse (indicated by arrows), subtract the offset of the first selected sample, and remove the linear trend of the seismogram (indicated by the dashed line). The area under the new pulse is used to set the bounds of the grid search in the spectral analysis described in the Data Processing section.
0 ; therefore, no taper is applied. The area under the pulse is used to determine the limits for $\Omega_{0}$ of the grid search described in the Moment Magnitude section. For the spectral analysis we zero-pad the displacement pulse to a length of 2048 samples. This allows us to sample the spectrum with higher resolution and to extrapolate the low-frequency spectral level toward lower frequencies. An interactive processing tool was developed to manually control the quality of fit to the theoretical displacement spectrum. It starts with the selection of unipolar displacement pulses and the removal of instrument response by deconvolution in the frequency domain. A fitting range of the far-field displacement spectrum can be selected and poor fits can be rejected, which for example fail due to high noise content present in the selected seismogram.

\section{Error Analysis}

For a comparison of magnitudes one should know the accuracy of magnitude determination and the factors that contribute most to magnitude uncertainty. In general, for mean $M_{\mathrm{L}}$ an uncertainty of 0.2 magnitude units is expected (e.g., Kanamori and Jennings, 1978, and Kanamori et al., 1993). In Basel, where the majority of earthquakes are $M_{\mathrm{L}}<2$, the magnitude values can be biased by the few recordings available. A previous study compared magnitudes of four broadband stations in the vicinity of Basel to magnitudes estimated using recordings from the entire network (Deichmann and Bachmann, 2007). The median offsets of those stations are $0.2,-0.2,-0.1$, and 0.5 magnitude units, respectively. The large deviation of 0.5 magnitude units is likely caused by the particularly energetic $S m S$ phase recorded at this station. As a consequence of these offsets smaller events are, on average, overestimated by 0.1 magnitude units when recordings of those four stations are available only. Thus, in the regression of $M_{\mathrm{L}}$ versus $M_{\mathrm{w}}$ we assume an uncertainty of 0.2 magnitude units in $M_{\mathrm{L}}$ above magnitude 2 and of 0.3 magnitude units for $M_{\mathrm{L}}<2$.

To assess how much the error of each parameter in equation (2) contributes to the epistemic uncertainty of $M_{\mathrm{w}}$, we performed a series of Monte Carlo simulations. We calculate 1000 realizations, using a normal distribution with the standard deviations given in Table 1 . The sensitivity of the radiation coefficient on the variations in strike, dip, and rake of the focal mechanisms as well as the uncertainty in azimuth and takeoff angle of the ray leaving the source are analyzed using equation 89 and the following equations in chapter 4 of Aki and Richards (2002). We distinguish two cases: first, we vary each parameter of equation (2) alone; second, we vary all parameters together. An example of our Monte Carlo analysis is plotted in Figure 4. We see that magnitudes are most sensitive to variations in the low-frequency level $\Omega_{0}$ and in the radiation coefficient $F_{\theta \Phi}$; a factor of 2 in uncertainty of $\Omega_{0}$ leads to an uncertainty of 0.2 in magnitude. The sensitivity to the radiation coefficient is given by the position of a station with respect to the nodal plane: the smaller 
Table 1

Typical Values and Assumed Errors for Parameters in Equation (2)*

\begin{tabular}{lcc}
\hline \multicolumn{1}{c}{ Parameter } & Typical Value & Error \\
\hline$\rho_{\xi}\left(\mathrm{kg} / \mathrm{m}^{3}\right)$ & 2700 & 20 \\
$\rho_{x}\left(\mathrm{~kg} / \mathrm{m}^{3}\right)$ & 1970 & 50 \\
$\Omega_{0}(\mathrm{nms})$ & $1.3 \cdot 10^{4}$ & factor 2 \\
$v_{\xi}(\mathrm{km} / \mathrm{s})$ & 3.46 & 0.1 \\
$v_{x}(\mathrm{~km} / \mathrm{s})$ & $0.5-2.7$ & 0.5 \\
$R(\mathrm{~km})$ & 5 & 0.1 \\
$S$ & 2 & 0.05 \\
Strike/dip/rake & $12^{\circ} / 75^{\circ} /-13^{\circ}$ & $10^{\circ}$ \\
Azimuth/takeoff & $134^{\circ} / 156^{\circ}$ & $10^{\circ}$
\end{tabular}

*An example of how uncertainties of each parameter contribute to moment-magnitude uncertainty is shown in Figure 4.

the radiation coefficient, the more the assumed $10^{\circ}$ uncertainty in source angles (Table 1) contributes. In the case shown in Figure 4 the radiation coefficient has a value of $F_{\theta \Phi}=0.66$. The error in magnitude is \pm 0.09 . For a smaller radiation coefficient of 0.32 (borehole station HALTI), the error in magnitude would be \pm 0.16 . Variations in the velocity-density model and uncertainties in hypocentral dis- tance contribute less than 0.05 magnitude units to the overall uncertainty. The resulting errors in $M_{\mathrm{w}}$ determined from records of a single station range from 0.2 to 0.3 magnitude units, mainly depending on the location of the station with respect to the nodal plane.

We further investigate the station-to-station scatter of moment magnitude for single events and whether a particular station has a bias toward a higher or lower magnitude. We first calculate moment magnitudes using mean radiation coefficients of 0.52 for $P$ and 0.63 for $S$ waves (Aki and Richards, 2002) and compare these with magnitude estimates of events for which radiation coefficients are obtained from focal mechanisms. The result of such a comparison for one event is shown in Figure 5. To test for systematic station biases, we compute the difference between the magnitude estimate at a specific station and the mean over all stations. The results are shown in Figure 6. For 22 out of 27 stations, the magnitude estimated at a particular station matches the mean magnitude over all stations within one standard deviation. For two stations, however, the bias is greater than 0.2 magnitude units. In general, the standard deviation for individual moment magnitudes is $\sim 0.15$ (Fig. 6). Combining the results of Figures 5 and 6 we observe that detailed focal mechanism

BALST
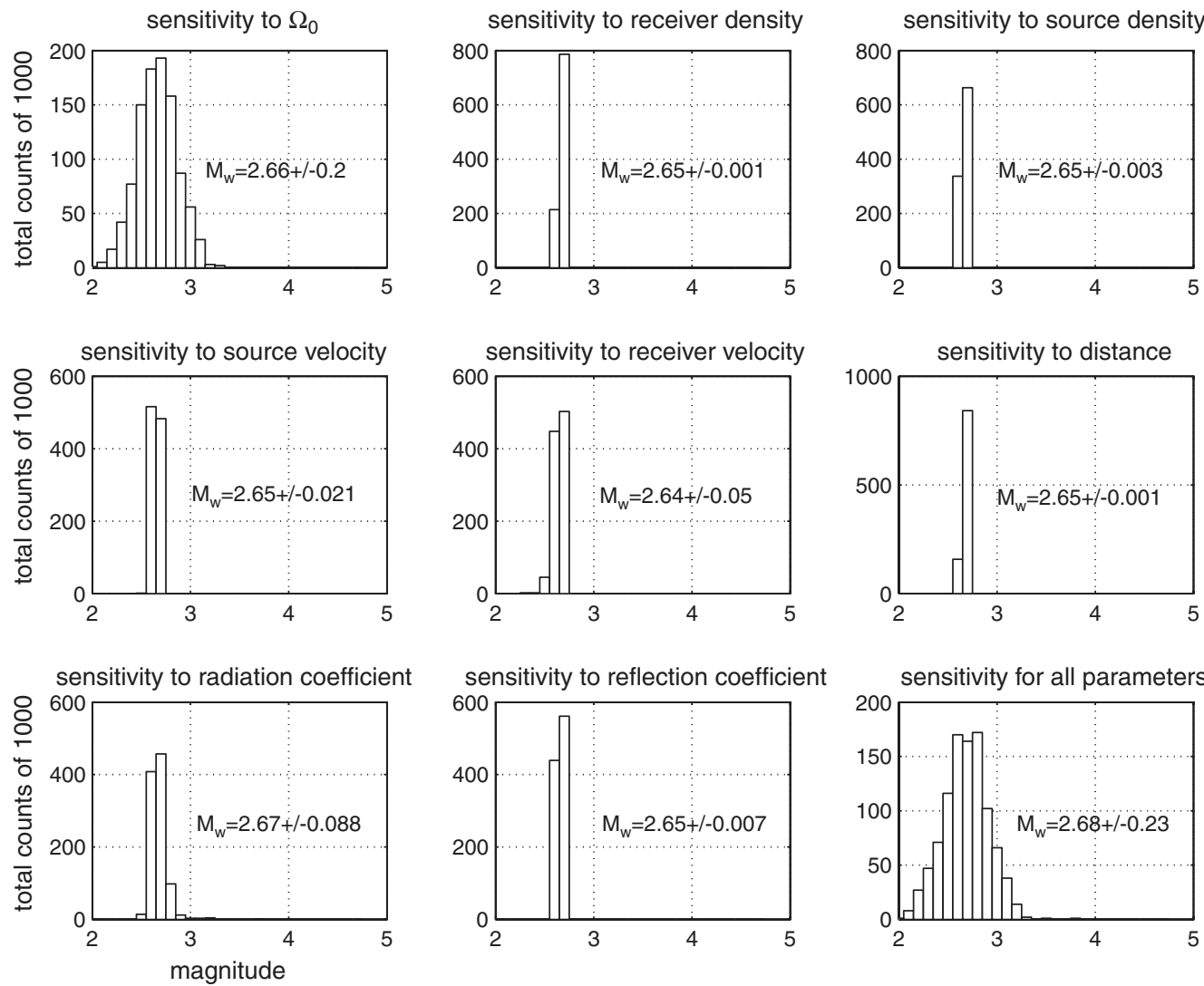

Figure 4. Histograms for the sensitivity study of a station at a hypocentral distance of $29 \mathrm{~km}$ (radiation coefficient 0.66 ). A Monte Carlo approach was used to test the contribution of the error in each parameter in equation (2) to the overall uncertainty of moment magnitude. In the first 8 panels only a single parameter was varied, while all the others were kept constant. In the last histogram all parameters were varied. Main contributors to magnitude uncertainty are errors in the estimation of $\Omega_{0}$ and uncertainty in radiation coefficient. 
(a)

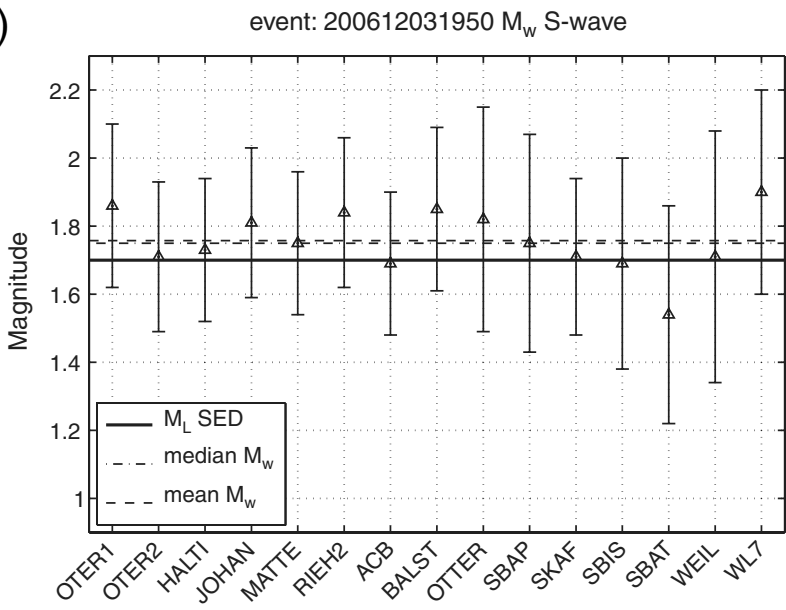

(b)

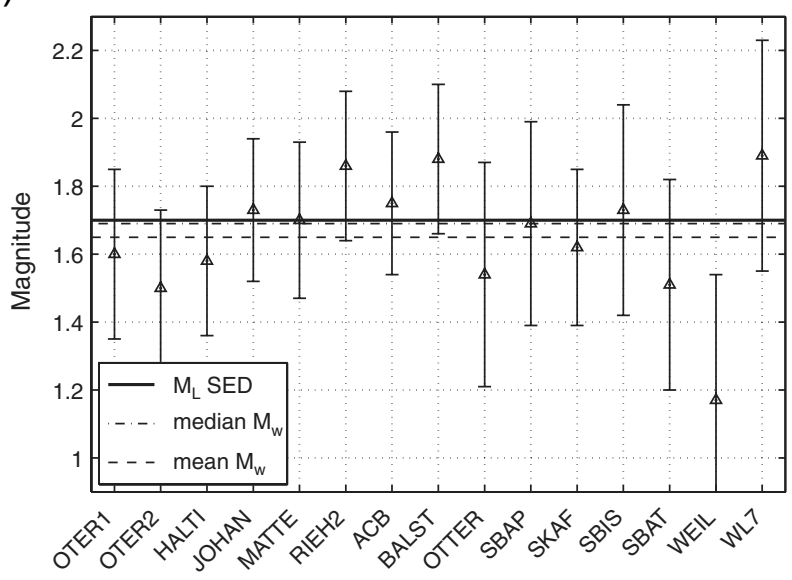

Figure 5. $\quad M_{\mathrm{w}}$ for each station for a single event using (a) individually determined radiation coefficient values and (b) average radiation coefficients of 0.63 for the presented $S$ wave. Using focal mechanism information reduces the scatter between individual magnitudes at each station, best seen at station WEIL (second from the right). Error bars represent one standard deviation in each direction.

information leads to better constrained magnitudes, but correcting for the radiation pattern alone is insufficient to entirely account for the observed magnitude offset between stations.

\section{Magnitude Scaling Results}

We plot local magnitude versus moment magnitude based on the Basel data in Figure 7. For the regression we use a weighted total least squares algorithm after Krystek and Anton (2007), a method that adjusts for errors in both $x$ and $y$ directions. The regression of $M_{\mathrm{L}}$ versus $M_{\mathrm{w}}$ results in a coefficient of proportionality $m$ equal to $1.58 \pm 0.08$. Note that local magnitude is only computed to one-digit accuracy, resulting in a discretized, patternlike appearance in Figure 7. The relation of $M_{\mathrm{L}}$ versus $M_{\mathrm{w}}$ can be well fit by a straight line, while a quadratic fit as in Grünthal et al. (2009) results in similar misfit values. The scatter between data points increases for $M_{\mathrm{L}} \leq 2$, caused by fewer available recordings to constrain $M_{\mathrm{L}}$ in that magnitude range and by a larger number of events with unknown focal mechanisms (leading to a larger error in $M_{\mathrm{w}}$ ). The proportionality factor of 1.58 clearly differs from an extrapolation of Hanks and Kanamori (1979), where they show that $M_{\mathrm{L}}$ and $M_{\mathrm{w}}$ agree above magnitude 3 . The deviation toward a magnitudedependent scaling for magnitudes below 3 can be explained either by source effects, such as increasing stress drop or increasing rupture velocity with moment, or path effects such as scattering and anelastic attenuation (e.g., Deichmann, 2006). The contribution of source and path to the observed scaling of magnitudes is examined in detail in the section Comparison with Theoretical Model.

\section{Wood-Anderson Amplitudes versus Low-Frequency Spectral Levels for Sequences of Similar Earthquakes}

In the previous section we examined the scaling of moment magnitude and local magnitude for induced events below the city of Basel. The dataset is well suited for a more detailed source-scaling analysis as the events occurred in a rather small source volume, and the data were recorded by a dense network of stations, providing the opportunity to properly account for path effects. Figure 7 shows that for $M_{\mathrm{L}} \geq 2$ data points are closely aligned along a straight line. However, despite a selection of high-quality waveforms and manual quality control, the scatter of data points for $M_{\mathrm{L}}<2$ could not be removed. In the following analysis of sequences of similar earthquakes, we take advantage of the fact that for such sequences some of the main contributors to magnitude uncertainty, such as site effects and uncertainty in radiation coefficients, can be eliminated.

\section{Sequences of Similar Earthquakes}

In an analysis of the spatial and temporal evolution of the induced seismicity in Basel, Deichmann and Giardini (2009) identified clusters of similar earthquakes. In particular, they find a sequence of nine events that are similar to the strongest $\left(M_{\mathrm{L}} 3.4\right)$ event. Using borehole data, we expand the analysis to a sequence of 52 similar events, including events with magnitudes as low as $M_{\mathrm{w}} 0.4$. All events show a high degree of similarity, visually demonstrated by the record sections and quantified in terms of cross-correlation coefficients (see the Appendix).

In terms of focal mechanism, the induced events are not different from natural seismicity in the area (Deichmann and Ernst, 2009; Deichmann and Giardini, 2009). Moreover, Ripperger et al. (2009) find no unusual features from modeling intensities of the strongest induced event. Thus, we conclude that the scaling relation for small events derived from the induced seismicity is representative also for spontaneously occurring earthquakes. Nevertheless, for a comparison to the artificially induced events, we also investigate five sequences of similar earthquakes of natural origin that occurred in Switzerland from 2001 to 2009 (Fig. 1). The 


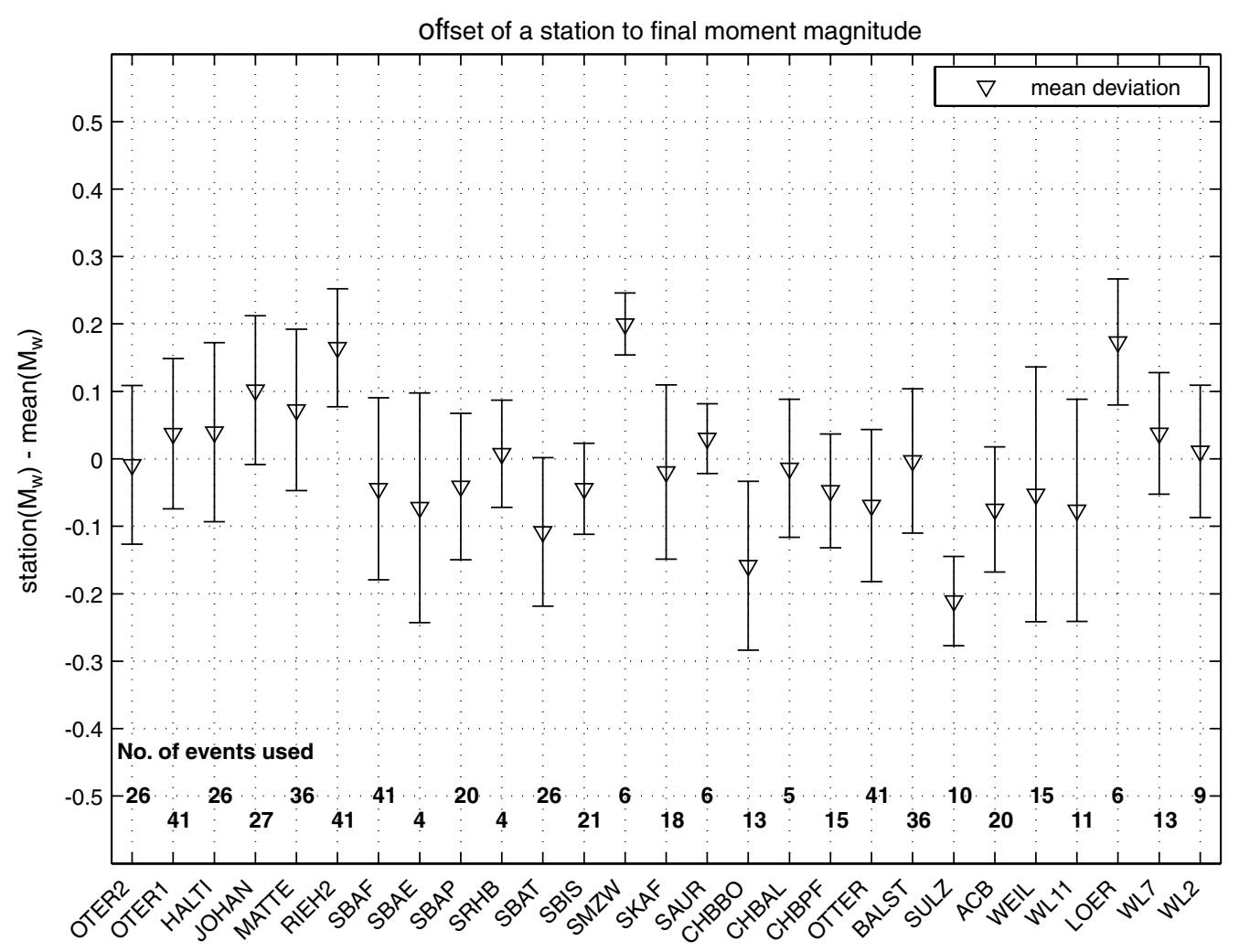

Figure 6. Offset of $M_{\mathrm{w}}$ of a single station compared with mean magnitude over all stations and all events where a focal mechanism could be determined (Basel sequence $S_{g}$ wave). The number of events lists how often a station was picked for magnitude estimation. For example, using the $S_{g}$ wave for $M_{\mathrm{w}}$ calculation at station SMZW by itself would estimate the magnitude by 0.2 units too high, whereas using only station SULZ would lead to magnitude estimates of 0.2 units too low on the average. Stations are listed by type and distance. OTER2 to RIEH2 are borehole stations, stations starting with $S$ are strong-motion stations as well as station OTTER, stations starting with CH are part of a temporary strong-motion network. BALST, SULZ, and ACB are broadband stations. WEIL, WL2, WL7, WL11, WL12, and LOER are stations of the German network.

sequences consist of up to 51 events covering the magnitude range between 0.6 and 4.1. All sequences are characterized by a high similarity of waveforms and by well-constrained focal mechanisms of the largest magnitude events in each cluster. The datasets for all individual earthquake sequences are described in detail in the Appendix.

\section{Simplification of Scaling Relations for Series of Similar Earthquakes}

In the analysis of spectral properties and scaling relations for sequences of similar earthquakes, we can exploit the similarity in source and path, assuming identical velocity and density information at the source and along the wave paths. Also the radiation coefficient and surface amplification can be considered identical for each station in the sequence. The scaling relation of $M_{\mathrm{L}}$ versus $M_{\mathrm{w}}$ then simplifies to a relation of WA amplitude versus spectral amplitude, which we derive in the following.

Local magnitude $M_{\mathrm{L}}$ is given as

$$
M_{\mathrm{L}}=\log A-\log A_{0} .
$$

In practice, $A$ is the maximum amplitude of the WoodAnderson seismogram at a particular station, and $-\log A_{0}$ is a function of hypocentral distance $R_{\xi x}$ accounting for amplitude decay with distance from the source. For sequences of similar earthquakes that share a common hypocentral location, the latter can be treated as a constant, and we can write

$$
M_{\mathrm{L}}=\log A+C_{1} \text {. }
$$

The high-pass character of the Wood-Anderson seismograph may lead to anomalously low $M_{\mathrm{L}}$ values compared with $M_{\mathrm{w}}$ for events with low stress drops or low rupture velocities and magnitudes above 3 , for which the dominant signal frequency approaches the natural frequency of the instrument $(1.25 \mathrm{~Hz})$. Values below magnitude 3 represent the majority of our dataset, and their local magnitudes are thus not affected by such saturation effects. Of the events analyzed, 14 are in the magnitude range $3 \leq M_{\mathrm{L}} \leq 4.1$; however, for these events the bias due to this effect is less than $5 \%$ in $M_{\mathrm{L}}$ as shown in Deichmann (2006).

Inserting equation (2) in equation (1), we obtain

$$
M_{\mathrm{w}}=\frac{2}{3} \log \left(\frac{4 \pi \rho_{\xi}^{1 / 2} \rho_{x}^{1 / 2} v_{\xi}^{5 / 2} v_{x}^{1 / 2}}{F_{\theta \Phi} S} R_{\xi x} \Omega_{0}\right)-6.03 .
$$


Comparison $M_{L}$ vs. $M_{W}$ using 195 events $S$ wave

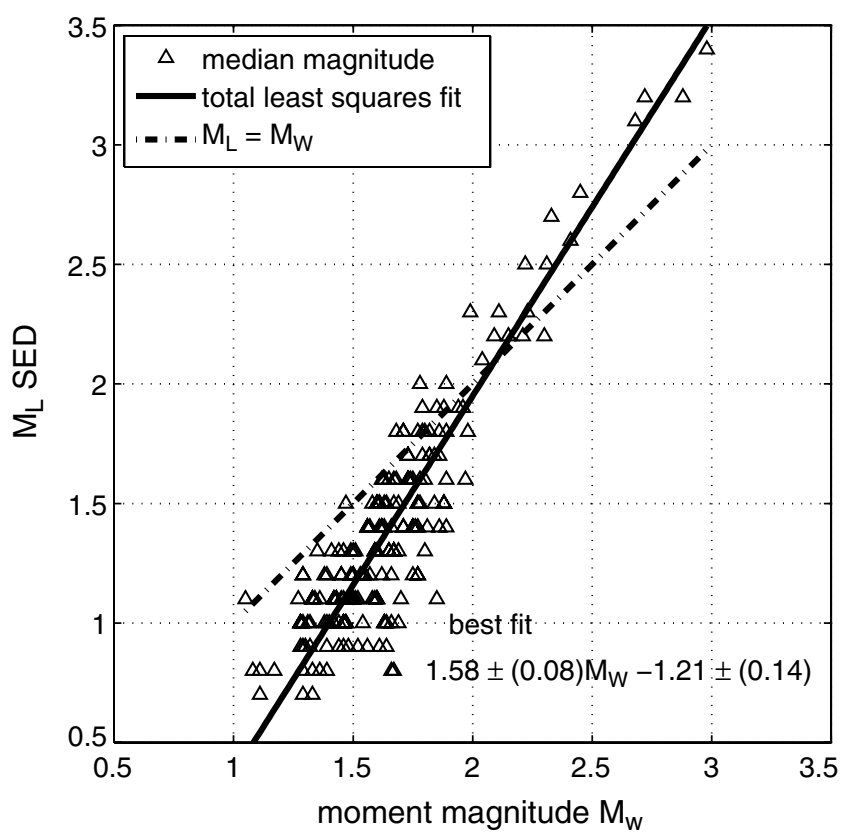

Figure 7. $M_{\mathrm{L}}$ versus $M_{\mathrm{w}}$ for the Basel sequence, using $S$ wave for moment-magnitude estimation. Errors of $M_{\mathrm{w}}$ and $M_{\mathrm{L}}$ are in the order of 0.25 magnitude units. For clarity we do not plot error bars in this figure; however, errors in each point are included in the fitting procedure. A linear fit sensitive to errors in $x$ and $y$ direction was used to fit the data. $M_{\mathrm{L}}$ is computed to one-digit accuracy resulting in a discretized pattern on the ordinate.

For sequences of similar earthquakes recorded at a given station, the source and receiver velocities and densities, the radiation coefficient, surface amplification, and distance are considered identical. Two-thirds the logarithm of their product in equation (6), plus the constant term of (1) can be set to a constant $C_{2}$, so that we obtain

$$
M_{\mathrm{w}}=\frac{2}{3} \log \left(\Omega_{0}\right)+C_{2}
$$

Therefore, for similar earthquakes recorded at the same station the assumption of $M_{\mathrm{L}}=m M_{\mathrm{w}}+C_{3}$ reduces to

$$
\log A=\frac{2}{3} m \log \left(\Omega_{0}\right)+C,
$$

where constants $C_{1}, C_{2}$, and $C_{3}$ are absorbed into constant $C$. A 1:1 relation in magnitude therefore corresponds to a $1: \frac{2}{3}$ relation in amplitudes. On the other hand, the scaling of $M_{\mathrm{L}} \propto 1.5 M_{\mathrm{w}}$ obtained in the previous section for the induced seismicity in Basel implies a 1:1 scaling between $\log A$ and $\log \Omega_{0}$.

The data processing used to obtain the relation of WA amplitude to $\Omega_{0}$ is identical to that described in the Data Processing section. Bounds for the grid search used to match spectral amplitude with a theoretical spectrum are derived from the pulse width and area under the curve of the unipolar far-field displacement pulse. For WA amplitude we assume a $20 \%$ error in amplitude, determined by sampling theoretical seismograms with high-frequency content and low signal-tonoise ratios $(<2: 1)$. Waveforms that are not similar by visual inspection and show low cross-correlation coefficients are not considered.

\section{Amplitude Scaling}

Figure 8 shows WA amplitude versus spectral amplitude $\left(\Omega_{0}\right)$ measurements for the borehole station HALTI for the sequence of similar earthquakes induced by fluid injection in Basel. The regression gives a proportionality factor of $(1.03 \pm 0.06)$ in amplitude scaling, which corresponds to a relation of $M_{\mathrm{L}} \propto(1.55 \pm 0.09) M_{\mathrm{w}}$. The latter value agrees closely with the scaling factor of $M_{\mathrm{L}} \propto 1.58( \pm 0.08) M_{\mathrm{w}}$ obtained from the regression through the median magnitudes over all stations and events shown in Figure 7. Moreover, the comparison of Figures 7 and 8 shows that the scatter of the data points at lower magnitudes has decreased significantly.

The results for the Basel sequence as well as for the series of earthquakes of natural origin are summarized in Tables 2 and 3. A representative plot of WA amplitude versus spectral amplitude for each sequence and a compilation of results for all stations that recorded eight or more events of the induced seismicity in Basel are plotted in Figure 9.

The scaling factor of Wood-Anderson amplitude versus $\Omega_{0}$ varies between $0.98 \pm 0.13$ for the strong-motion

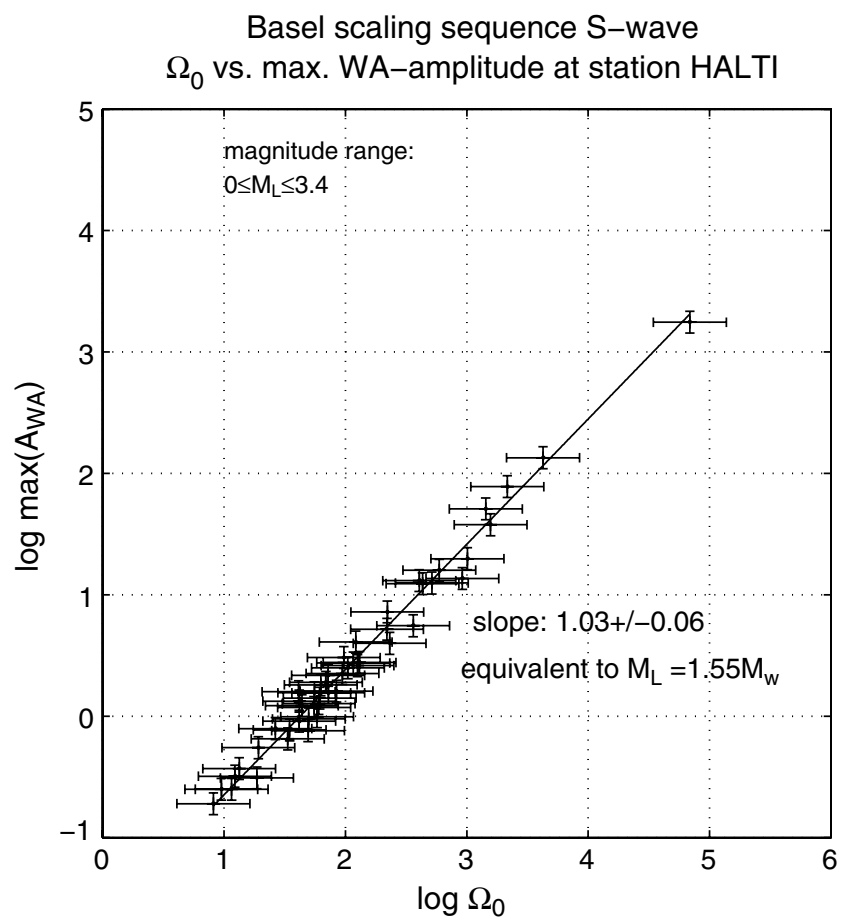

Figure 8. Wood-Anderson amplitude versus spectral amplitude at low frequency for a sequence of earthquakes similar to the strongest event of the Basel sequence recorded at station HALTI. The converted site-specific scaling factor of 1.55 differs only slightly from the overall scaling factor of 1.58 in the previous figure. 
Table 2

Scaling Coefficients of WA Amplitude versus Spectral Amplitude for the Sequence of Similar Earthquakes in Basel Induced by Water Injection

\begin{tabular}{|c|c|c|c|c|c|}
\hline Sequence & Station & $P / S$ & $\begin{array}{l}\text { Number of } \\
\text { Events Used }\end{array}$ & $\begin{array}{l}\text { Hypocentral } \\
\text { Distance }\end{array}$ & $\begin{array}{c}A_{\mathrm{WA}} \text { versus } \Omega_{0} \\
\text { Proportionality Factor }\end{array}$ \\
\hline \multirow[t]{14}{*}{ Basel $P_{g}$ Wave $-0.6 \leq M_{\mathrm{L}} \leq 3.4$} & OTER2 & $P_{q}$ & 21 & $2.1 \mathrm{~km}$ & $1.21 \pm 0.15$ \\
\hline & OTER1 & $P_{g}$ & 44 & $4.2 \mathrm{~km}$ & $1.06 \pm 0.07$ \\
\hline & HALTI & $P_{g}^{g}$ & 19 & $4.8 \mathrm{~km}$ & $1.10 \pm 0.13$ \\
\hline & JOHAN & $P_{g}^{g}$ & 26 & $4.8 \mathrm{~km}$ & $1.14 \pm 0.18$ \\
\hline & SBAF & $P_{q}^{y}$ & 7 & $4.9 \mathrm{~km}$ & $0.99 \pm 0.22$ \\
\hline & OTTER & $P_{g}$ & 8 & $5.1 \mathrm{~km}$ & $1.07 \pm 0.18$ \\
\hline & SBAP & $P_{g}^{g}$ & 4 & $5.6 \mathrm{~km}$ & $1.12 \pm 0.19$ \\
\hline & MATTE & $P_{g}^{g}$ & 25 & $5.8 \mathrm{~km}$ & $1.12 \pm 0.17$ \\
\hline & RIEH2 & $P_{g}^{g}$ & 7 & $5.9 \mathrm{~km}$ & $1.17 \pm 0.15$ \\
\hline & SBIS & $P_{g}$ & 7 & $7.0 \mathrm{~km}$ & $1.06 \pm 0.17$ \\
\hline & CHBBO & $P_{g}^{g}$ & 6 & $8.0 \mathrm{~km}$ & $1.05 \pm 0.17$ \\
\hline & CHBAL & $P_{g}^{g}$ & 4 & $8.9 \mathrm{~km}$ & $1.12 \pm 0.21$ \\
\hline & BALST & $P_{g}^{g}$ & 4 & $29.2 \mathrm{~km}$ & $1.05 \pm 0.20$ \\
\hline & SULZ & $P_{g}^{g}$ & 6 & $39.8 \mathrm{~km}$ & $1.12 \pm 0.17$ \\
\hline \multirow{15}{*}{ Basel $S_{g}$ Wave $-0.6 \leq M_{\mathrm{L}} \leq 3.4$} & OTER2 & $S_{g}^{g}$ & 30 & $2.1 \mathrm{~km}$ & $1.05 \pm 0.13$ \\
\hline & OTER1 & $S_{g}^{9}$ & 47 & $4.2 \mathrm{~km}$ & $1.07 \pm 0.07$ \\
\hline & HALTI & $S_{g}^{g}$ & 48 & $4.8 \mathrm{~km}$ & $1.03 \pm 0.06$ \\
\hline & JOHAN & $S_{g}^{g}$ & 49 & $4.8 \mathrm{~km}$ & $1.04 \pm 0.06$ \\
\hline & SBAF & $S_{g}^{g}$ & 9 & $4.9 \mathrm{~km}$ & $0.98 \pm 0.13$ \\
\hline & OTTER & $S_{g}^{g}$ & 8 & $5.1 \mathrm{~km}$ & $1.06 \pm 0.14$ \\
\hline & SBAP & $S_{g}^{g}$ & 6 & $5.6 \mathrm{~km}$ & $1.05 \pm 0.17$ \\
\hline & SBAT & $S_{g}$ & 5 & $5.8 \mathrm{~km}$ & $1.02 \pm 0.17$ \\
\hline & MATTE & $S_{g}$ & 52 & $5.8 \mathrm{~km}$ & $1.01 \pm 0.06$ \\
\hline & RIEH2 & $S_{g}^{g}$ & 48 & $5.9 \mathrm{~km}$ & $1.10 \pm 0.07$ \\
\hline & CHBRI & $S_{g}^{g}$ & 8 & $6.9 \mathrm{~km}$ & $1.09 \pm 0.29$ \\
\hline & SBIS & $S_{g}$ & 6 & $7.0 \mathrm{~km}$ & $1.00 \pm 0.16$ \\
\hline & SMZW & $S_{g}^{g}$ & 4 & $7.6 \mathrm{~km}$ & $1.07 \pm 0.26$ \\
\hline & SAUR & $S_{g}$ & 4 & $12.3 \mathrm{~km}$ & $1.04 \pm 0.18$ \\
\hline & $\mathrm{ACB}$ & $S_{g}^{g}$ & 4 & $50.0 \mathrm{~km}$ & $1.00 \pm 0.22$ \\
\hline
\end{tabular}

station SBAF (Basel sequence $S_{g}$ wave) and $1.33 \pm 0.16$ for the broadband station DAVOX (Sertig sequence $P_{g}$ wave) (Tables 2 and 3). In total, 51 out of 57 regressions show amplitude scaling factors between 0.98 and 1.15 . This translates to factors of 1.47 and 1.73 in the scaling of $M_{\mathrm{L}}$ versus $M_{\mathrm{w}}$. For each sequence the proportionality factors of WA amplitude versus $\Omega_{0}$ match within one standard deviation $(\sigma)$ between stations. For all sequences and stations proportionality factors match within two $\sigma$ bounds.

A prominent outlier is the proportionality factor in $P$-wave amplitude at station DAVOX in the Sertig sequence (1.33). The takeoff angle of the $P$ wave first arrival to this station is close to the nodal plane of the focal mechanism. The radiation coefficient of the direct $P$ wave is low (0.03), the signal-to-noise ratio is low and the scatter in the data increases. A slight change in source mechanism produces significantly different waveforms and introduces scatter to amplitude scaling. As a consequence, in the case of station DAVOX, the $P$ wave of the strongest events could not be used; therefore, the magnitude range of processed events for the $P$ wave had to be restricted to magnitudes between 0.6 and 2.8. The resulting scatter in the data and the smaller fitting range lead to the high scaling factor of 1.33 , with a relatively large uncertainty of \pm 0.16 . In comparison, for the $S$ wave, the radiation coefficient at that station is high (0.9). The signal-to-noise ratio is high, and events in the whole magnitude range between 0.6 and 3.9 show similar waveforms. Therefore, scatter in the data is low and the uncertainty in proportionality factor reduces to \pm 0.07 (Fig. 9).

As we are also comparing sequences of different depths and different focal mechanisms, we can investigate a possible influence of these parameters on the amplitude scaling. Out of the six sequences, four sequences show a predominantly strike-slip mechanism (Basel, Martigny, Glarey, and Thusis); the Sertig sequence exhibits a normal-faulting mechanism, and for the series of Brugg, the source mechanism is either lateral motion or oblique normal faulting. In general, hypocentral depths of the sequences ranges between $5 \mathrm{~km}$ and $8 \mathrm{~km}$, with the exception of the Brugg sequence, where the focal depth is $20 \mathrm{~km}$. However, within the uncertainty of the measurements we see no influence of focal mechanism or depth on the amplitude scaling.

\section{Comparison with Theoretical Model}

With the intention of estimating source and path effects and their effect on the observed scaling relation we compare our findings to a simple theoretical model. We measure 
Table 3

Scaling Coefficients of WA Amplitude versus Spectral Amplitude for Sequences of Similar Earthquakes of Natural Origin in Switzerland

\begin{tabular}{|c|c|c|c|c|c|}
\hline Sequence & Station & $P / S$ & $\begin{array}{c}\text { Number of } \\
\text { Events Used }\end{array}$ & $\begin{array}{l}\text { Hypocentral } \\
\text { Distance }\end{array}$ & $\begin{array}{c}A_{\mathrm{WA}_{\mathrm{A}}} \text { vs. } \Omega_{0} \\
\text { Proportionality Factor }\end{array}$ \\
\hline \multirow[t]{4}{*}{ Martigny $1.1 \leq M_{\mathrm{L}} \leq 3.6$} & DIX & $P_{g}$ & 26 & $31.1 \mathrm{~km}$ & $1.12 \pm 0.09$ \\
\hline & EMV & $S_{g}$ & 25 & $15.4 \mathrm{~km}$ & $1.05 \pm 0.12$ \\
\hline & AIGLE & $S_{g}$ & 49 & $25.3 \mathrm{~km}$ & $1.13 \pm 0.12$ \\
\hline & DIX & $S_{g}$ & 9 & $31.0 \mathrm{~km}$ & $1.03 \pm 0.10$ \\
\hline \multirow{5}{*}{ Sertig $0.6 \leq M_{\mathrm{L}} \leq 3.9$} & DAVOX & $P_{g}$ & 44 & $10.5 \mathrm{~km}$ & $1.33 \pm 0.16$ \\
\hline & FUORN & $P_{g}$ & 23 & 35.7 km & $1.20 \pm 0.10$ \\
\hline & BERNI & $P_{g}$ & 13 & $37.4 \mathrm{~km}$ & $1.08 \pm 0.14$ \\
\hline & DAVOX & $S_{g}$ & 50 & $10.5 \mathrm{~km}$ & $1.10 \pm 0.07$ \\
\hline & VDL & $S_{g}$ & 12 & $38.7 \mathrm{~km}$ & $1.04 \pm 0.14$ \\
\hline \multirow[t]{7}{*}{ Glarey $0.6 \leq M_{\mathrm{L}} \leq 3.9$} & SENIN & $P_{g}^{g}$ & 34 & $8.2 \mathrm{~km}$ & $1.15 \pm 0.09$ \\
\hline & DIX & $P_{g}$ & 13 & $26.9 \mathrm{~km}$ & $1.14 \pm 0.14$ \\
\hline & SALAN & $P_{g}^{g}$ & 5 & $33.5 \mathrm{~km}$ & $1.08 \pm 0.23$ \\
\hline & SENIN & $S_{g}$ & 34 & $8.2 \mathrm{~km}$ & $1.07 \pm 0.09$ \\
\hline & GRYON & $S_{g}$ & 29 & $20.2 \mathrm{~km}$ & $1.10 \pm 0.07$ \\
\hline & LKBD & $S_{g}$ & 28 & $24.5 \mathrm{~km}$ & $1.14 \pm 0.08$ \\
\hline & DIX & $S_{g}$ & 21 & $26.9 \mathrm{~km}$ & $1.09 \pm 0.11$ \\
\hline \multirow[t]{6}{*}{ Brugg $0.7 \leq M_{\mathrm{L}} \leq 4.1$} & $\mathrm{ACB}$ & $P_{g}$ & 12 & $22.3 \mathrm{~km}$ & $1.15 \pm 0.08$ \\
\hline & ZUR & $P_{g}$ & 6 & $40.8 \mathrm{~km}$ & $1.13 \pm 0.14$ \\
\hline & $\mathrm{ACB}$ & $S_{g}$ & 11 & $22.3 \mathrm{~km}$ & $1.04 \pm 0.07$ \\
\hline & ZUR & $S_{g}$ & 9 & $40.8 \mathrm{~km}$ & $1.09 \pm 0.09$ \\
\hline & SLE & $S_{g}$ & 8 & $42.1 \mathrm{~km}$ & $1.04 \pm 0.07$ \\
\hline & BALST & $S_{g}$ & 7 & $45.6 \mathrm{~km}$ & $1.12 \pm 0.12$ \\
\hline \multirow[t]{6}{*}{ Thusis $0.5 \leq M_{\mathrm{L}} \leq 4.0$} & VDL & $P_{g}$ & 23 & $32.0 \mathrm{~km}$ & $1.10 \pm 0.09$ \\
\hline & PLONS & $P_{g}^{g}$ & 23 & $32.8 \mathrm{~km}$ & $0.98 \pm 0.10$ \\
\hline & DAVOX & $P_{g}$ & 15 & $34.0 \mathrm{~km}$ & $1.05 \pm 0.10$ \\
\hline & VDL & $S_{g}$ & 7 & $32.0 \mathrm{~km}$ & $1.21 \pm 0.39$ \\
\hline & PLONS & $S_{g}$ & 28 & $32.8 \mathrm{~km}$ & $1.21 \pm 0.10$ \\
\hline & DAVOX & $S_{g}$ & 29 & $34.0 \mathrm{~km}$ & $1.24 \pm 0.08$ \\
\hline
\end{tabular}

WA amplitude versus spectral amplitude for a set of source time functions, propagated through an attenuating twolayered half-space.

Wave propagation is represented by convolving the farfield displacement pulse with causal $Q$ operators (Azimi et al., 1968). We choose a two-layer model as a simplified model of the geology beneath the city of Basel. The bottom layer corresponds to crystalline basement, which is covered by compacted sediments of $2.5 \mathrm{~km}$ thickness. $Q$ values for the top layer are determined by spectral division and amplitude decay measurements at borehole stations OTER2 $(2740 \mathrm{~m})$, OTER $1(500 \mathrm{~m})$, and surface station OTTER situated on top of each other. Both methods result in similar $Q$ values for $P$ and $S$ waves between 35 and 50 for four investigated events between magnitude 0.9 and 2.2. For the following calculations we use $Q=50$ for the sediment layer. $Q$ values for the bottom layer are obtained by forward modeling. A theoretical source time function is propagated through the anelastic medium; the resulting waveform is compared with waveform recordings at station OTER2. For comparison we choose a magnitude 0.5 event with a unipolar $P$-wave displacement waveform. The source time function is generated from a circular source with variable rupture velocity as proposed by Sato (1994) and extended by Deichmann (1997). Input parameters are moment $\left(M_{0}\right)$, phase velocity at the source $(c)$, stress drop $(\Delta \sigma)$, average rupture velocity $\left(\bar{v}_{r}\right)$, the rates of the duration of rupture acceleration and deceleration relative to the total rupture time $\left(k_{1}, k_{2}\right)$, respectively, steepness of velocity increase $(q)$, and angle between ray and fault normal $(\theta)$. The moment is estimated as in equation (2), $c$ is given by borehole $\operatorname{logs}(c=5940 \mathrm{~m} / \mathrm{s})$, $\theta=72^{\circ}$ is calculated for the given focal mechanisms with a 2D raytracing program as described in Deichmann and Ernst (2009), $q=1, k_{1}=40 \%$, and $k_{2}=10 \%$ are chosen to obtain an emergent onset of the modeled $P$ wave. Source parameters $\Delta \sigma, \bar{v}_{r}$ and $Q$ for the path are varied during forward modeling to minimize the misfit between the attenuated source time function and the radial component of the $P$ wave at borehole sensor OTER2 (at a hypocentral distance of $2.5 \mathrm{~km})$. The forward modeling results suggest $\Delta \sigma=$ $3 \mathrm{MPa}, \bar{v}_{r}=1.25 \mathrm{~km} / \mathrm{s}$, and $Q=800$ as best-fitting parameters; however, a large trade-off exists among those parameters. A change in stress drop by a factor of 8 is compensated by a factor of 2 in $\bar{v}_{r}$, and even a variation in $Q$ by a factor of 2 in the range $400 \leq Q \leq 800$ has only a small influence on the misfit (11\%). Despite the trade-off among forward modeling parameters, the effect of a variation of these parameters on the scaling of WA amplitude versus $\Omega_{0}$ is minor compared with the effect of attenuation of the sediment layers on top of the crystalline basement $\left(Q=50, d_{\text {sed }}=2.5 \mathrm{~km}\right)$. 

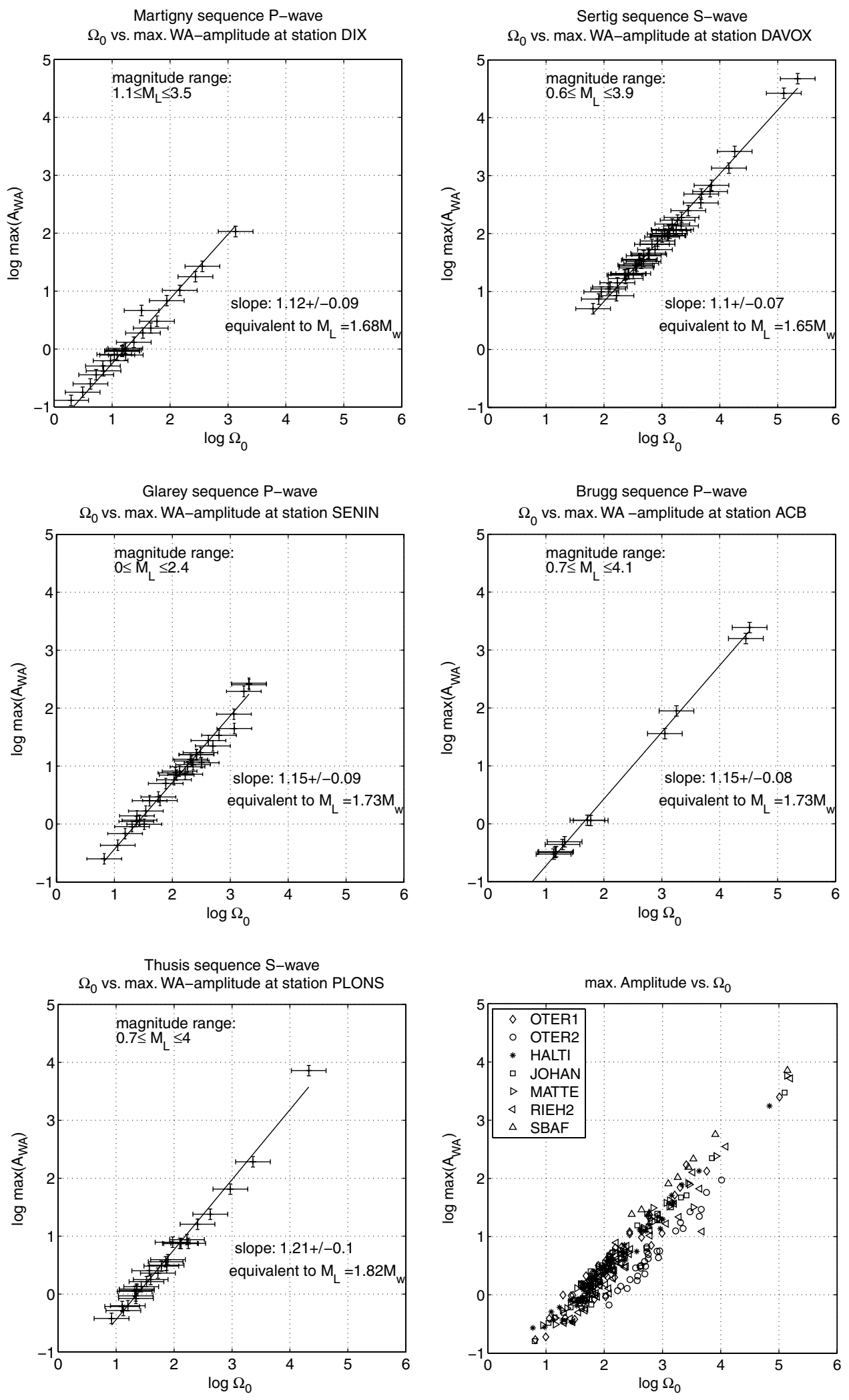

Figure 9. Wood-Anderson amplitude versus spectral amplitude at low frequency for selected stations of sequences of similar earthquakes. The bottom right picture shows a compilation of results for stations that recorded 8 or more earthquakes of the Basel sequence. 
To calculate the theoretical scaling of WA amplitude versus $\Omega_{0}$, we use events in the magnitude range of $0 \leq$ $M_{\mathrm{w}} \leq 4$, using the previously described setup. To estimate contributions of path effects to the scaling between WA amplitude and spectral amplitude, we compare simulations for elastic media (no $Q$ ) and simulations with anelastic media, while keeping the stress drop of $3 \mathrm{MPa}$ constant (Ide and Beroza, 2001). Average rupture velocity $\bar{v}_{r}$ is also assumed to be constant over all magnitudes. Alternatively, to investigate the effect of a systematic change of stress drop with moment, we vary stress drop at a rate of $\left(\Delta \sigma \sim M_{0}^{0.25}\right)$ following Mayeda and Walter (1996). The results are plotted in Figure 10 for a two half-space layered model consisting of a granitic lower layer of $2.5 \mathrm{~km}$ thickness $\left(Q_{P, S}=800\right.$, $\rho_{\mathrm{gr}}=2700 \mathrm{~kg} / \mathrm{m}^{3}, \bar{v}_{r}=2500 \mathrm{~m} / \mathrm{s}, v_{p}=5490 \mathrm{~m} / \mathrm{s}$, and $v_{s}=3460 \mathrm{~m} / \mathrm{s}$ ) and a sediment layer of $2.5 \mathrm{~km}$ thickness $\left(Q_{P, S}=50, \rho_{\text {sed }}=2560 \mathrm{~kg} / \mathrm{m}^{3}, v_{p}=3480 \mathrm{~m} / \mathrm{s}\right.$, and $v_{s}=$ $2620 \mathrm{~m} / \mathrm{s}$ ). The solid line shows amplitude scaling for a constant stress drop of $3 \mathrm{MPa}$ and the dashed line for increasing stress drop with moment $(0.53 \mathrm{MPa} \leq \Delta \sigma \leq 5.3 \mathrm{MPa}$ for $\left.0 \leq M_{\mathrm{w}} \leq 4\right)$. For comparison with real data we approximate the theoretical relationship by three linear regression lines to demonstrate the variation in proportionality factor in case a

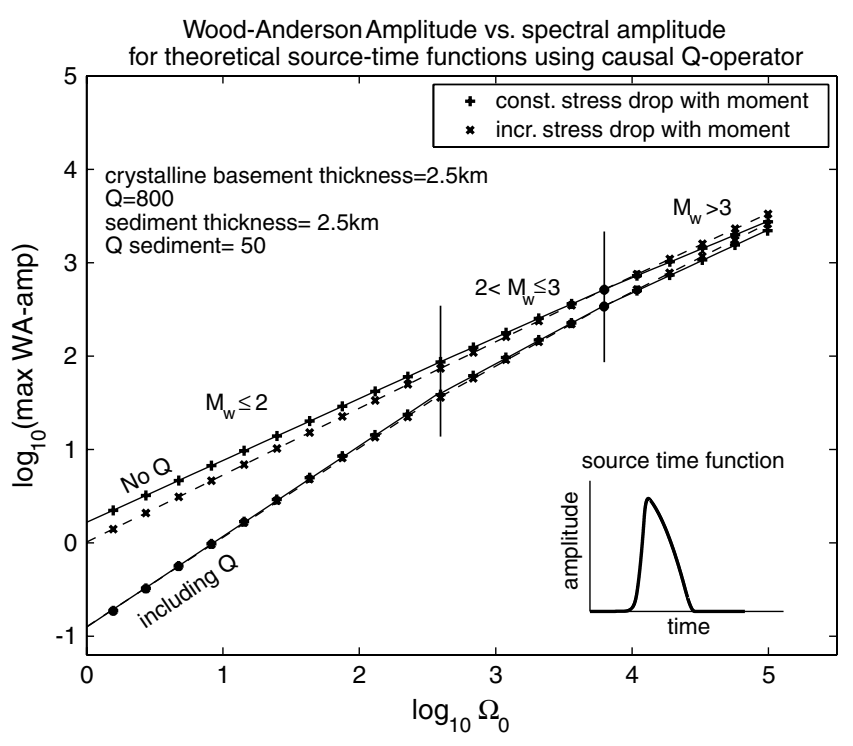

Figure 10. Theoretical analysis of scaling of WA amplitude versus $\Omega_{0}$. Source time functions similar to the one shown in the small inset (bottom right) are propagated through a two-layered media. The result is a nonlinear relation that is approximated by three linear relations separated into corresponding magnitude intervals. The $\mathbf{x}$ symbol shows the relation if an increasing stress drop with moment is chosen $(0.53 \mathrm{MPa}-5.3 \mathrm{MPa}$ for $M=$ $0.0-M=4.0$ ) versus a constant $\Delta \sigma$ of $3 \mathrm{MPa}$ (the + symbol). The proportionality factors between WA amplitude and $\Omega_{0}$ for all curves (listed from top to bottom) are: (1) WA $\sim 0.67 \Omega_{0}$ $(M<2$, no $Q$, const. $\Delta \sigma)$; (2) WA $\sim 0.72 \Omega_{0}(M<2$, no $Q$, incr. $\Delta \sigma)$; (3) WA $\sim 0.97 \Omega_{0} \quad(M<2$, incl. $Q$, const. $\Delta \sigma)$; (4) WA $\sim 0.96 \Omega_{0} \quad(M<2$, incl. $Q$, incr. $\Delta \sigma)$; (5) WA $\sim 0.61 \Omega_{0}$ $(M>3$, no $Q$, const. $\Delta \sigma)$; (6) WA $\sim 0.68 \Omega_{0}$ ( $M>3$, no $Q$, incr. $\Delta \sigma)$; (7) WA $\sim 0.68 \Omega_{0} \quad(M>3$, incl. $Q$, const. $\Delta \sigma)$; $(8)$ WA $\sim 0.74 \Omega_{0}(M>3$, incl. $Q$, incr. $\Delta \sigma)$. linear approximation within a certain magnitude range is chosen. The first regression is carried out for magnitudes $M_{\mathrm{w}} \leq 2$, the second in the magnitude range $2<M_{\mathrm{w}} \leq 3$, and a third for magnitudes $M_{\mathrm{w}}>3$. For magnitudes $M_{\mathrm{w}} \leq 2$ the proportionality factor between WA amplitude and $\Omega_{0}$ in the case of attenuating media and constant stress drop over all magnitudes is 0.97 (Basel model). It decreases to 0.81 in the magnitude range $2<M_{\mathrm{w}} \leq 3$ and is 0.68 for magnitudes $M_{\mathrm{w}}>3$. As the majority (>90\%) of investigated earthquakes for the Basel sequence have magnitudes $M_{\mathrm{w}}<2$, we compare the proportionality factor of 0.97 to the empirically determined values in Table 2 . At 24 out of 29 stations the observed scaling factors match the theoretical value of 0.97 within one standard deviation $(0.07<\sigma<0.2)$.

To model amplitude scaling for sequences of natural origin we change the setup to a homogenous half-space and place our receivers at $30 \mathrm{~km}$ hypocentral distance. We obtain similar results to the Basel case. In either case the effect of anelastic attenuation is dominant compared with increasing stress drop with seismic moment $\left(\Delta \sigma \sim M_{0}^{0.25}\right)$. The variation of $\Delta \sigma$ with moment at the rate of $M_{0}^{0.25}$ while keeping $\bar{v}_{r}$ fixed is equivalent to varying $\bar{v}_{r}$ by a factor of 2.15 over the range of $0 \leq M_{\mathrm{w}} \leq 4$ and keeping $\Delta \sigma$ fixed.

To estimate the contribution of the WA filter to the curvature of the scaling, we repeat all calculations without filter. The difference is negligible for magnitudes below 3 and increases to a difference of $14 \%$ in proportionality factor for the highest magnitude $\left(M_{\mathrm{L}} 4.1\right)$ in this study.

\section{Summary and Discussion}

We compared local magnitude and moment magnitude for 195 induced earthquakes in the Basel region. A detailed error analysis identifies the major contributors to momentmagnitude uncertainty, namely the uncertainty of source angles (strike, dip, rake, ray-azimuth, and takeoff angle) and the spectral fit of the amplitude at low frequency. Using focal mechanism information reduces the scatter of individual moment magnitudes at each station; however, some systematic station offsets and in particular a general scatter between local and moment magnitude below magnitude 2 remains. The scatter is significantly reduced by focusing on a series of similar earthquakes, in which case certain error sources, such as different travel paths and site effects, cancel. The $M_{\mathrm{L}}-M_{\mathrm{w}}$ relation simplifies to a relation of WoodAnderson amplitude versus low-frequency spectral amplitude. For almost all stations and sequences we obtain a proportionality factor $\sim 1$ in amplitude scaling, which corresponds to a relation of $M_{\mathrm{L}} \sim 1.5 M_{\mathrm{w}}$ in magnitude scaling. Theoretical simulations show that the transition from a $1: 1$ magnitude scaling to a scaling of 1:1.5 for magnitudes below 2 can be attributed to anelastic attenuation. Source effects (e.g., constant stress drop versus increasing stress drop with moment) have a minor effect on the observed scaling behavior. We also compare results based on induced events to those of natural origin. We find no difference in magnitude 
scaling. Studies of Deichmann and Ernst (2009) and Deichmann and Giardini (2009) that investigate focal mechanisms and spatial and temporal evolution of the induced seismicity attribute events to shear failure on preexisting faults. Also ground motion and intensities observed for the strongest induced event in Ripperger et al. (2009) show no unusual features. We therefore conclude that induced seismicity is well suited to investigate magnitude scaling.

The scaling of $M_{\mathrm{L}}$ to $M_{\mathrm{w}}$, or equivalently $M_{0}$, has been an issue in many studies over the past years. In a source parameter study of 157 injection-induced microearthquakes at the KTB Deep Drilling Site in Germany, Jost et al. (1998) find $M_{\mathrm{L}} \sim 1.49 M_{\mathrm{w}}$ in the range of $-2 \leq M_{\mathrm{L}} \leq 1.2$. Their findings match the proportionality factor of $1.58 \pm(0.08)$ that we find in our study of induced events in Basel in the magnitude range of $0.7 \leq M_{\mathrm{L}} \leq 3.4$ (Fig. 7). Other studies, where the majority of magnitudes are below 4 , find similar values. For example, Archuleta et al. (1982) find $M_{\mathrm{L}} \sim$ $1.56 \pm(0.1) M_{\mathrm{w}}$ for $3 \leq M_{\mathrm{L}} \leq 6$, in a study of source parameters for 40 earthquakes within a sequence of 1500 events at Mammoth Lakes, California; Kim et al. (1989) find $M_{\mathrm{L}} \sim$ $1.49 \pm(0.05) M_{\mathrm{w}}$ for earthquakes in the magnitude range of $2 \leq M_{\mathrm{L}} \leq 5.2$, in a study of source parameters for earthquakes in the Baltic Shield. Many other studies find values between 1 and 1.9 over various magnitude ranges (see Deichmann [2006] and Hanks and Boore [1984] for a compilation). Our simulations (Fig. 10) show that the proportionality factor of $M_{\mathrm{L}}$ versus $M_{\mathrm{w}}$ increases toward lower magnitudes. In our study the range in magnitudes is rather small; therefore, a linear relation is sufficient to fit the data in this magnitude range. For a wider range of magnitudes than in this study, a polynomial fit used by Grünthal et al. (2009) or Stromeyer et al. (2004) is better suited to capture the nonlinear relation of local versus moment magnitude.

These magnitude studies show that in practice $M_{\mathrm{L}} \neq M_{\mathrm{w}}$. As pointed out by Deichmann (2006), a deviation from the 1:1 scaling for earthquakes with magnitudes below about 3 can be due either to frequency-dependent attenuation along the propagation path or to magnitudedependent variations of stress drop and rupture velocity. To estimate the influence of source and path effects on magnitude scaling, we compared calculations based on a constant stress drop with moment to calculations assuming an increasing stress drop with moment. We show that in practice the effect of anelastic attenuation is dominant compared to this modeled stress-drop effect for magnitudes $M<2$. We therefore were not able to resolve the question of whether stress drop scales with moment or remains constant. For magnitudes $M>3$, however, a change of stress drop with moment leads to a difference in proportionality factor, and the effect of anelastic attenuation is no longer dominant. Increasing stress drop with moment leads to a scaling factor of 1.11 versus 1.03 (Fig. 10) for magnitudes above 3. For a sufficient number of similar earthquakes in this magnitude range, with an increased number of recordings and therefore reduced uncertainties in proportionality factor, stress-drop scaling may be discernible. However, for the dataset of this study, where the majority of magnitudes are below 2, a deviation in scaling cannot be observed within the uncertainty of the scaling factor.

The conversion of $M_{\mathrm{L}}$ to $M_{\mathrm{w}}$ is important for magnitude recurrence calculations. In plots of the logarithm of cumulative number of earthquakes versus magnitude (GutenbergRichter plot), deviations from a linear relation ( $b$ value) are an indicator of magnitude incompleteness. Changes in $b$ value are seen as an indicator for incomplete datasets or point to errors in magnitude. In the past, recurrence plots were based on $M_{\mathrm{L}}$. For updating the new $M_{\mathrm{w}}$-based seismic hazard map of Switzerland, $M_{\mathrm{L}}$ is converted to $M_{\mathrm{w}}$ by adding a constant offset (Braunmiller et al., 2005). Our study shows that for small magnitudes $\left(M_{\mathrm{L}}<3\right)$ this practice is not justified. As a consequence, given a Gutenberg-Richter relation that is linear for $M_{\mathrm{L}}$, a magnitude-dependent conversion of $M_{\mathrm{L}}$ to $M_{\mathrm{w}}$ will lead to a break in the linearity of the Gutenberg-Richter relation based on the converted $M_{\mathrm{w}}$ values. Thus, $b$ values derived mainly from converted moment magnitudes below about 3 will tend to be higher than $b$ values based on larger events. This fact must be taken into consideration in seismic hazard calculations for low-tomoderate seismicity areas (such as Switzerland), as well as for estimates of the time it takes for the seismic activity induced by geothermal reservoir stimulation to return to background seismicity levels. The conversion of $M_{\mathrm{L}}$ to $M_{\mathrm{w}}$ for magnitudes below 2 and its implications on recurrence rates will gain importance with the increase of geothermal and $\mathrm{CO}_{2}$ sequestration projects in the future. The scaling results for small earthquakes presented in this paper have been incorporated into a new $M_{\mathrm{L}}-M_{\mathrm{w}}$ conversion relation for Switzerland that spans the magnitude range $0.2<M_{\mathrm{L}}<$ 6 (Goertz-Allmann et al., unpublished manuscript, 2010).

\section{Data and Resources}

Surface seismograms used in this study were collected by the Swiss Seismological Service and the Erdbebendienst des Landesamtes für Geologie, Rohstoffe und Bergbau Baden Württemberg and are available upon request.

Recordings of the borehole seismometers were provided by Geopower Basel and are proprietary. They cannot be released to the public.

Plots including maps were made using the Generic Mapping Tools version 4.3.1 (www.soest.hawaii.edu/gmt; Wessel and Smith, 1998).

\section{Acknowledgments}

We thank Geothermal Explorers Limited for the access to their borehole logs and $1000 \mathrm{~Hz}$ data as well as instrument specifications. We also thank Bettina Allmann, Ben Edwards, and Toni Kraft for fruitful discussions, and two anonymous reviewers who helped to improve the manuscript. The project was funded by the Swiss National Science Foundation (SNF 200021-112284/1). 


\section{References}

Abercrombie, R. E. (1995). Earthquake source scaling relationships from -1 to $5 M_{L}$ using seismograms recorded at 2.5-km depth, J. Geophys. Res. 100, 24,015-24,036.

Aki, K., and P. Richards (2002). Quantitative Seismology Second Ed., University Science Books, Sausalito, California.

Archuleta, R. J., E. Cranswick, C. Mueller, and P. Spudich (1982). Source parameters of the 1980 Mammoth Lakes, California, earthquake sequence, J. Geophys. Res. 72, 4595-4607.

Asanuma, H., Y. Kumano, A. Hotta, U. Schanz, H. Niitsuma, and M. Häring (2007). Analysis of microseismic events from a stimulation at Basel, Switzerland, GRC Transactions 31, 265-269.

Azimi, S., A. Kalinin, V. Kalinin, and B. Pivovarov (1968). Impulse and transient characteristics of media with linear and quadratic absorption laws, Izvestiya Phys. Solid Earth 2, 88-93.

Baer, M., N. Deichmann, J. Braunmiller, S. Husen, D. Fäh, D. Giardini, P. Kästli, U. Kradolfer, and S. Wiemer (2005). Earthquakes in Switzerland and surrounding regions during 2004, Eclogae geol. Helv. 98, 407-418.

Bakun, W. H. (1984). Seismic moments, local magnitudes, and codaduration magnitudes for earthquakes in central California, Bull. Seismol. Soc. Am. 74, no. 2, 439-458.

Boatwright, J. (1980). A spectral theory for circular seismic sources; simple estimates of source dimension, dynamic stress drop and radiated seismic energy, Bull. Seismol. Soc. Am. 70, 1-27.

Boore, D. M. (1989). The Richter scale: Its development and use for determining earthquake source parameters, Tectonophysics 166, 1-14.

Braunmiller, J., N. Deichmann, D. Giardini, and S. Wiemer (2005). Homogeneous moment-magnitude calibration in Switzerland, Bull Seismol. Soc. Am. 95, no. 1, 58-74.

Brune, J. N. (1970). Tectonic stress and seismic shear waves from earthquakes, J. Geophys. Res. 75, 4997-5009.

Clinton, J., E. Hauksson, and K. Solanki (2006). An evaluation of the SCSN moment tensor solutions: Robustness of the $M_{\mathrm{w}}$ magnitude scale, style of faulting, and automation of the method, Bull Seismol. Soc. Am. 96, no. $5,1689-1705$.

Deichmann, N. (1997). Far-field pulse shapes from circular sources with variable rupture velocities, Bull Seismol. Soc. Am. 87, no. 5, $1288-1296$.

Deichmann, N. (2006). Local magnitude, a moment revisited, Bull. Seismol. Soc. Am. 96, no. 4, 1267-1277.

Deichmann, N., and C. Bachmann (2007). Evaluation of the induced seismicity in Basel 2006/2007: Locations, magnitudes, focal mechanisms, statistical forecasts and earthquake scenarios, Report of the Swiss Seismological Service to Geopower AG, Switzerland, 152 pp.

Deichmann, N., and J. Ernst (2009). Earthquakes focal mechanisms of the induced seismicity in 2006 and 2007 below Basel (Switzerland), Swiss J. Geosci. 102, no. 3, 457-466.

Deichmann, N., and D. Giardini (2009). Earthquakes induced by the stimulation of an enhanced geothermal system below Basel (Switzerland), Seismol. Res. Let. 80, no. 5, 784-798.

Deichmann, N., M. Baer, J. Braunmiller, D. B. Dolfin, F. Bay, F. Bernardi, B. Delouis, D. F. Fäh, M. Gerstenberger, D. Giardini, S. Huber, U. Kradolfer, S. Maraini, I. Oprsal, R. Schibler, T. Schler, S. Sellami, S. Steimen, S. Wiemer, J. Wössner, and A. Wyss (2002). Earthquakes in Switzerland and surrounding regions during 2001, Eclogae geol. Helv. 95, 249-261.

Deichmann, N., M. Baer, J. Braunmiller, C. Cornou, D. Fäh, D. Giardini, M. Gisler, S. Huber, S. Husen, P. Kästli, U. Kradolfer, M. Mai, S. Maraini, I. Oprsal, T. Schler, D. Schorlemmer, S. Wiemer, J. Wössner, and A. Wyss (2004). Earthquakes in Switzerland and surrounding regions during 2003, Eclogae geol. Helv. 97, 447-458.

Deichmann, N., J. Clinton, S. Husen, F. Haslinger, D. Fäh, D. Giardini, P. Kästli, U. Kradolfer, I. Marschall, and S. Wiemer (2009). Earthquakes in Switzerland and surrounding regions during 2008, Swiss J. Geosci. 102, no. 3, 505-514.
Diehl, T., S. Husen, E. Kissling, and N. Deichmann (2009). High-resolution 3-d $P$-wave model of the Alpine crust, Geophys J. Int. 179, 1133-1147.

Dyer, B., U. Schanz, F. Ladner, M. Häring, and T. Spillmann (2008). Microseismic imaging of a geothermal reservoir stimulation, The Leading Edge 27, 856-869.

Esmersoy, C. (1984). Polarization analysis, orientation and velocity estimation in three component VSP, in M. N. Toksöz and R. R. Stewart (Editors), Vertical Seismic Profiling_Part B: Advanced Concepts, Geophysical Press, London.

Grünthal, G., and R. Wahlström (2003). An $M_{\mathrm{w}}$ based earthquake catalogue for central, northern and northwestern Europe using a hierarchy of magnitude conversions, J. Seismol. 7, 507-531.

Grünthal, G., R. Wahlström, and D. Stromeyer (2009). The unified catalogue of earthquakes in central, northern, and northwestern Europe (cenec)_Updated and expanded to the last millenium, J. Seismol 4, no. $13,517-541$.

Hanks, T. C., and D. M. Boore (1984). Moment-magnitude relations in theory and practice, J. Geophys. Res 89, no. B7, 6229-6235.

Hanks, T., and H. Kanamori (1979). A moment magnitude scale, J. Geophys Res. 84, 2348-2350.

Häring, M. O., U. Schanz, F. Ladner, and B. Dyer (2008). Characterization of the Basel 1 enhanced geothermal system, J. Geothermics 37, 469-495.

Havenith, H. B., D. Fäh, U. Polom, and A. Roullé (2007). S-wave velocity measurements applied to the seismic microzonation of Basel, Upper Rhine Graben, Geophys. J. Int. 170, 346-358.

Ide, S., and G. Beroza (2001). Does apparent stress vary with earthquake size?, Geophys. Res. Lett. 28, no. 17, 3349-3352.

Jackson, G., I. Mason, and S. Greenhalgh (1991). Principal component transforms of triaxial recordings by singular value decomposition, Geophysics 56, no. 4, 528-533.

Jost, M. L., T. Büßelberg, Ö. Jost, and H.-P. Harjes (1998). Source parameters of injection-induced microearthquakes at $9 \mathrm{~km}$ depth at the KTB deep drilling site, Germany, Bull Seismol. Soc. Am. 88, no. 3, $815-832$.

Joyner, W. B., R. E. Warrick, and T. E. Fumal (1981). The effect of quaternary alluvium on strong ground motion in the Coyote Lake, California, earthquake of 1979, Bull Seismol. Soc. Am. 71, no. 4, 1333-1349.

Kanamori, H., and P. Jennings (1978). Determination of local magnitude, $M_{\mathrm{L}}$, from strong motion accelerograms, Bull. Seismol. Soc. Am. 68, no. $2,471-486$.

Kanamori, H., J. Mori, E. Hauksson, T. H. Heaton, and L. K. Hutton (1993). Determination of earthquake energy release and $M_{\mathrm{L}}$ using Terrascope, Bull. Seismol. Soc. Am. 83, no. 2, 330-346.

Kastrup, U., M.-L. Zoback, N. Deichmann, K. Evans, D. Giardini, and A. Michael (2004). Stress field variations in the Swiss Alps and the northern Alpine foreland derived from inversion of fault plane solutions, J. Geophys. Res. 109, B01402, doi 10.1029/2003JB002, 550.

Kim, W., R. Wahlström, and M. Urski (1989). Regional spectral scaling relations of source parameters in the Baltic shield, Tectonophysics 166, 151-161.

Kradolfer, U., and D. Mayer-Rosa (1984). Attenuation of seismic waves in Switzerland, in Proceedings of the XIXth General Assembly of the European Seismological Commission, 481-488.

Krystek, M., and M. Anton (2007). A weighted total least-squares algorithm for fitting a straight line, Meas. Sci. Tech. 18, 3438-3442.

Kumano, Y., H. Asanuma, A. Hotta, H. Niitsuma, U. Schanz, and M. Häring (2007). Reservoir structure delineation by microseismic multiplet analysis at Basel, Switzerland, 2006, in Paper presented at the 77th SEG meeting, San Antonio, Texas, USA, Extended Abstracts, $1271-1276$.

Mayeda, K., and W. Walter (1996). Moment, energy, stress drop, and source spectra of western United States earthquakes from regional coda envelopes, J. Geophys. Res 101, no. B5, 11,195-11,208.

Morasca, P., K. Mayeda, L. Malagnini, and W. Walter (2005). Coda-derived source spectra, moment magnitudes and energy-moment scaling in the western Alps, Geophys. J. Int. 160, 263-275. 
Ripperger, J., P. Kästli, D. Fäh, and D. Giardini (2009). Ground motion and macroseismic intensities of a seismic event related to geothermal reservoir stimulation below the city of Basel: Observations and modelling, Geophys J. Int. 3, no. 179, 1757-1771.

Sato, T. (1994). Seismic radiation from circular cracks growing at variable rupture velocity, Bull Seismol. Soc. Am. 84, 1199-1215.

Scordilis, E. M. (2006). Empirical global relations converting $M_{\mathrm{S}}$ and $m_{\mathrm{b}}$ to moment magnitude, J. Seismol. 10, 225-236.

Stromeyer, D., G. Grünthal, and R. Wahlström (2004). Chi-square regression for seismic strength parameter relations, and their uncertainties, with applications to an $M_{\mathrm{w}}$ based earthquake catalogue for central, northern and northwestern Europe, J. Seismol. 1, no. 8, 143-153.

Wessel, P., and W. H. F. Smith (1998). New, improved version of Generic Mapping Tools released, Eos Trans. AGU 79, no. 47, 579.

\section{Appendix}

\section{The Earthquake Sequence of Basel}

The city of Basel was chosen for a deep heat mining geothermal project. Water was injected under high pressure at a depth of $5 \mathrm{~km}$ into the crystalline basement to increase the permeability for subsequent water circulation. Operations were stopped after an induced event of magnitude $M_{\mathrm{L}} 3.4$ was widely felt within the city of Basel, where macroseismic intensities reached IV to V on the EMS-98 intensity scale (Ripperger et al., 2009). Hypocenters of the induced events are mainly confined to a north-northwest-south-southeast oriented lens-shaped cloud, about $1 \mathrm{~km}$ in diameter and $200 \mathrm{~m}$ wide, at depths between 4 and $5 \mathrm{~km}$ (Fig. 2). Of the 49 focal mechanisms available to date, six are normalfaulting mechanisms and two are strike-slip mechanisms with a strong normal component; all others exhibit strike-slip mechanisms with more or less north-south east-west striking nodal planes (Deichmann and Ernst, 2009). In Figure A1 we give an overview of the network installed in Basel and show 52 seismograms for a sequence of similar earthquakes. A detailed overview of the project can be found in Häring et al. (2008). First analyses of the induced microseismicity have been published by Kumano et al. (2007), Asanuma et al. (2007), Dyer et al. (2008), and Deichmann and Giardini (2009).

\section{The Earthquake Sequence of Martigny}

A sequence of 27 earthquakes at a depth of $5 \mathrm{~km}$ was recorded during a period of 9 months in 2001 close to the city of Martigny in the lower Valais, southwest Switzerland. The magnitude of the strongest earthquakes reached $M_{\mathrm{L}} 3.6$ and $M_{\mathrm{L}}$ 3.5. Waveforms of all 27 events are very similar. The focal mechanisms of the strongest events are almost identical. In fact, all hypocenters are constrained to a single fault plane with a precision of a few tens of meters in relative depth and distance, using a high precision time-domain cross-correlation technique (Deichmann et al., 2002). Hypocenters align on a northeast-southwest striking fault plane with a maximum relative distance of $1.6 \mathrm{~km}$ and maximum relative depth difference of $1.2 \mathrm{~km}$. For a descrip- tive overview we plot the first eight seismograms of the sequence at station DIX, and a cross-correlation matrix of the processed, unfiltered $P$-wave intervals as they enter into the scaling investigation (Fig. A2).

\section{Sertig Sequence}

In 2003, a swarmlike sequence of 51 earthquakes occurred near the village of Sertig-Dörfli, $8 \mathrm{~km}$ south of Davos, eastern Switzerland (Fig. A3). The sequence occurred over two distinct time intervals: the first, consisting of 23 events, lasted for one week and included an $M_{\mathrm{L}} 3.6$ and an $M_{\mathrm{L}} 3.9$ event; after a pause of one week, activity resumed with an $M_{\mathrm{L}} 3.9$ event and a peak rate of 9 events in less than 12 hours after another 6 days. Based on $S$ - $P$ arrival-time differences observed at a temporary station installed close to the epicenter and comparing arrival times from Moho reflections at station MUO, the focal depth of the sequence is constrained to 6-8 km (Deichmann et al., 2004). Fault-plane solutions of the three strongest events $\left(M_{\mathrm{L}} 3.9,3.9\right.$, and 3.6) are constrained by numerous first-motion polarities and are almost identical. The rupture corresponds to a normalfaulting mechanism with northeast-southwest orientation of the $T$ axis. For all fault-plane solutions the orientation of the $T$ axis differs by less than $10^{\circ}$. The identification of the active fault plane failed as most of the rays to the stations at short epicentral distances have takeoff angles that are close to one of the nodal planes, resulting in low amplitudes of the $P$ wave.

\section{Glarey Sequence}

The sequence of Glarey in the Valais in southwest Switzerland occurred within 4 months in 2003, following a foreshock, mainshock, aftershock pattern. The strongest event of $M_{\mathrm{L}} 3.9$ was preceeded by a small $M_{\mathrm{L}} 0.7$ foreshock (Deichmann et al., 2004). Another 34 events were recorded subsequently, including an $M_{\mathrm{L}} 3.6$ event just 8 minutes after the main event. All earthquakes revealed a high degree of waveform similarity (Fig. A4). The focal depth of $6 \mathrm{~km}$ is well constrained using six strong-motion records within a radius of $8-12 \mathrm{~km}$ and broadband station SENIN at an epicentral distance of $5 \mathrm{~km}$. The depth is also confirmed by full waveform inversion (Baer et al., 2005). The faulting mechanism of the two strongest events in the sequence show a strike-slip mechanism with a north-northeast-southsouthwest oriented $T$ axis, which matches with orientations of previously recorded earthquakes in the northern Valais (Kastrup et al., 2004).

\section{Brugg Sequence}

The earthquakes near the city of Brugg in northern Switzerland occurred in 2003 and 2004 in an area that was previously assumed to be aseismic (Fig. A5). The first earthquake reached a local magnitude of 4.0. The focal depth of $20 \mathrm{~km}$ was well constrained by stations SULZ and ACB at epicentral distances of $4 \mathrm{~km}$ and $9 \mathrm{~km}$. Shaking intensities 

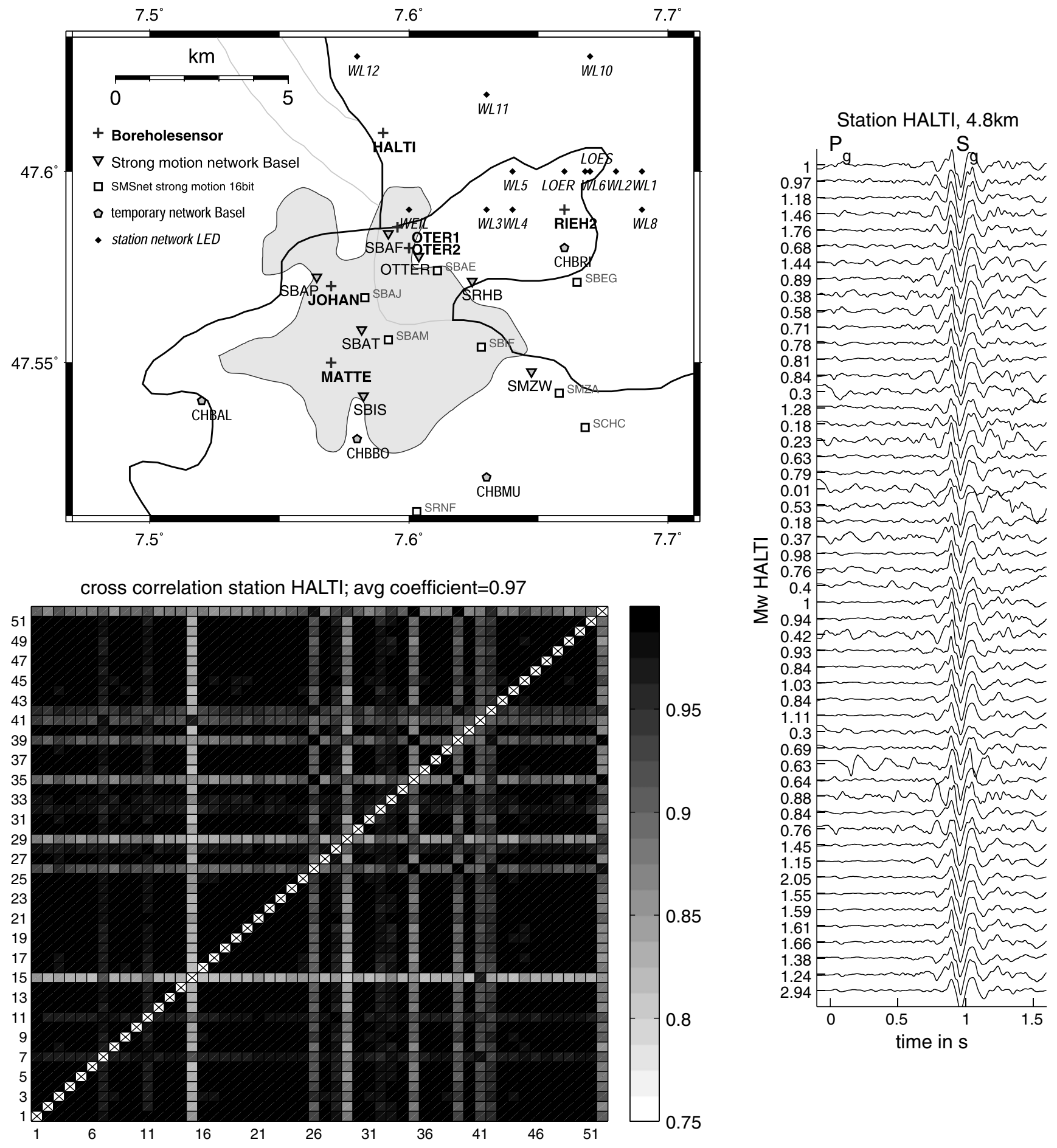

Figure A1. Station network in the city of Basel and examples of waveforms for a sequence of similar earthquakes recorded at borehole station HALTI at a depth of $550 \mathrm{~m}$ and hypocentral distance of $4.8 \mathrm{~km}$. The moment magnitude, $M_{\mathrm{w}}$, determined from the records at borehole sensor HALTI are listed next to each trace. The last event $\left(M_{\mathrm{w}} 2.94\right)$ is the $M_{\mathrm{L}} 3.4$ mainshock. Cross-correlation coefficients are plotted as grayscale for the $S_{g}$-wave interval used in the scaling analysis.

reached IV on the EMS-98 scale over large parts of northern Switzerland. According to Baer et al. (2005), the focal mechanism corresponds to either lateral motion on a shallow dipping north-northeast-south-southwest striking or oblique normal faulting on an almost vertical northwest-southeast striking fault plane. The orientation of the $T$ axis in an east-northeast-west-southwest direction agrees with the orientation of the regional deformation (Kastrup et al., 2004). The earthquake was followed by seven aftershocks ranging from $M_{\mathrm{L}} 0.7$ to $M_{\mathrm{L}}$ 2.7. The first four aftershocks 

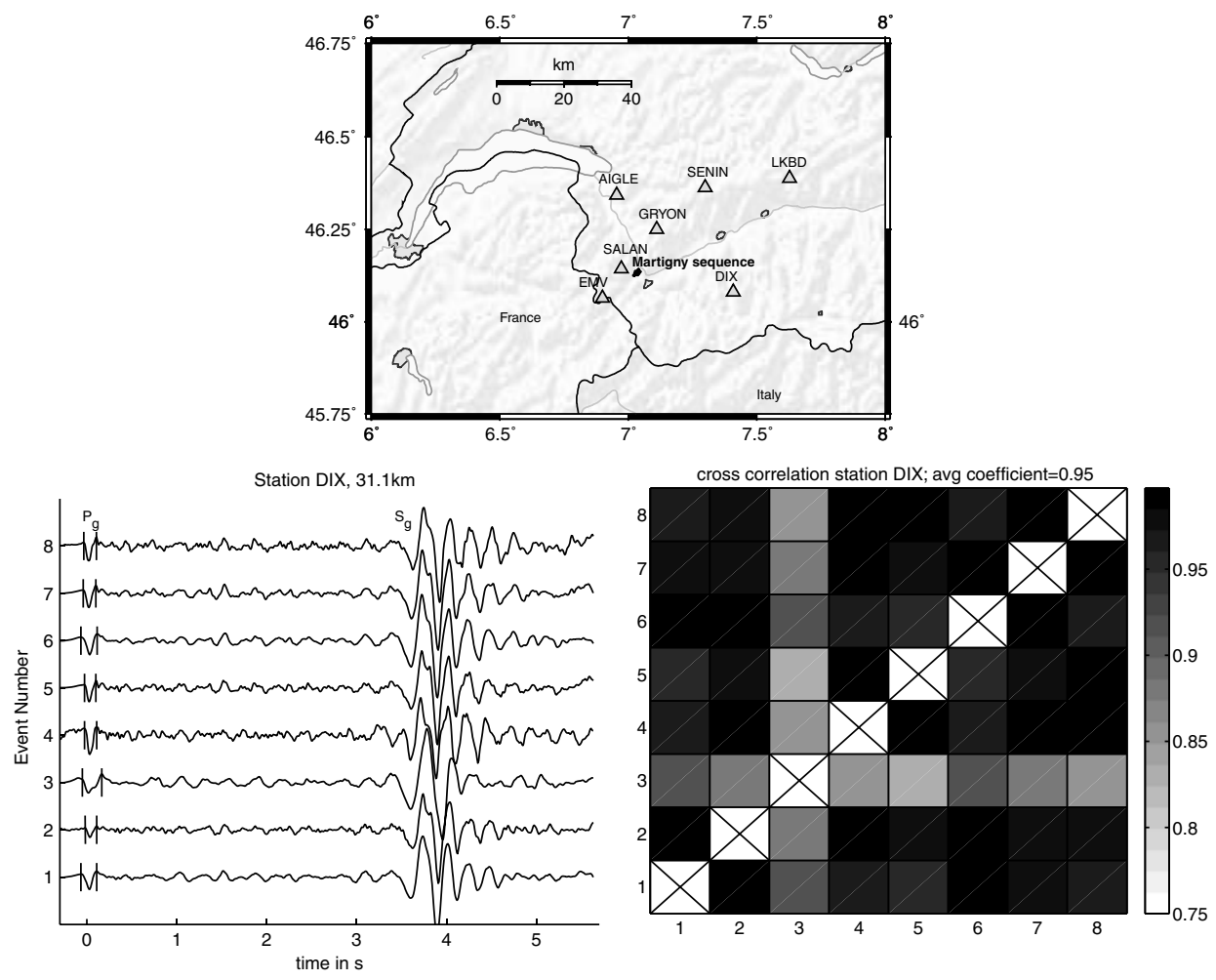

Figure A2. The Martigny sequence consists of 27 similar events. Shown are the first 8 seismograms of the sequence at station DIX in $29.5 \mathrm{~km}$ hypocentral distance, band-pass-filtered from 2 to $30 \mathrm{~Hz}$. The vertical lines indicate the interval used for waveform analysis. On the right we show cross-correlation coefficients for the processed $P$-wave intervals (see the Data Processing section) used for investigation.
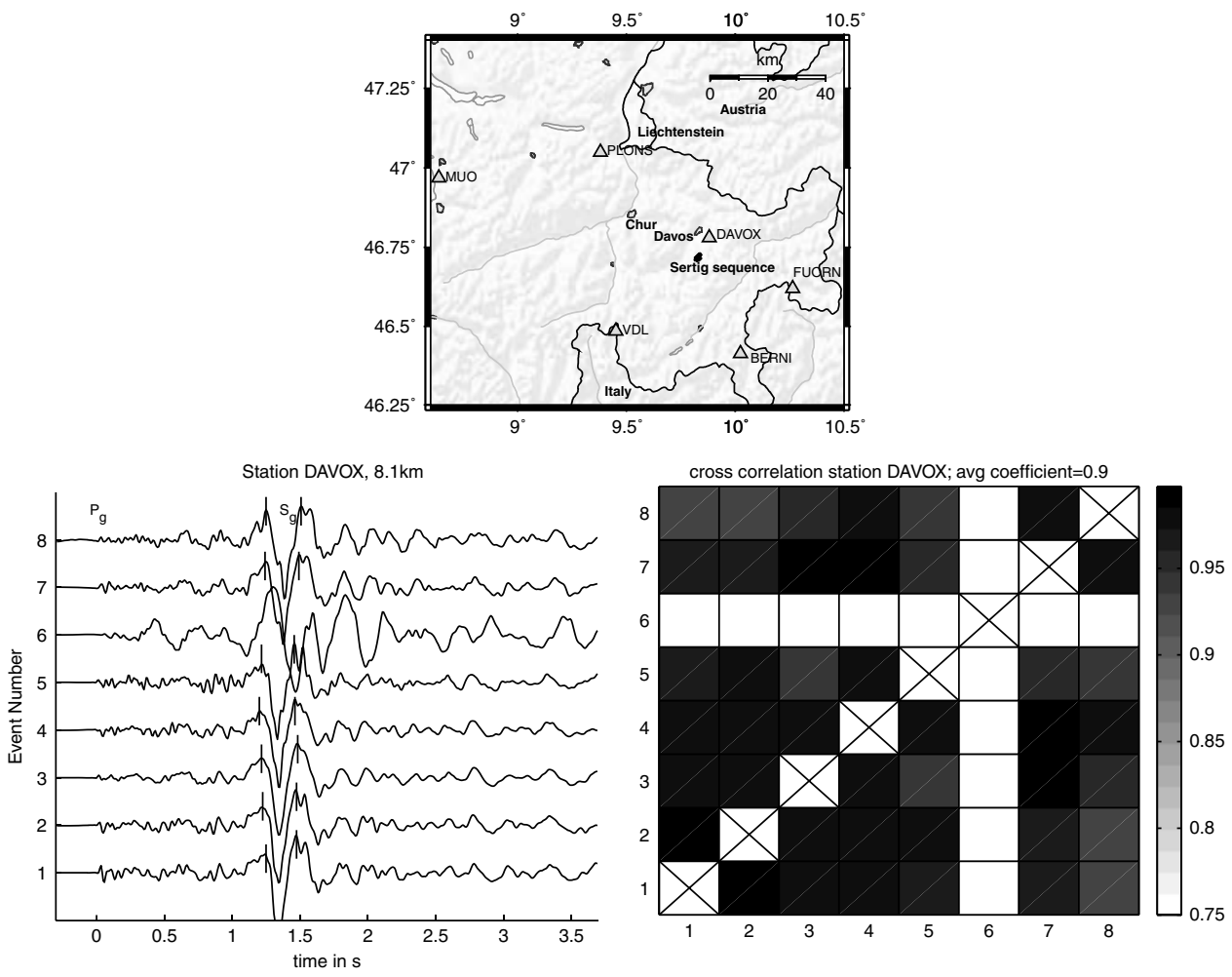

Figure A3. The swarmlike Sertig sequence consists of 51 similar events that occurred within four months in 2003. Shown are the first 8 seismograms of the sequence at station DAVOX in $8.1 \mathrm{~km}$ hypocentral distance. Intervals used for processing are marked by vertical lines. Event 6 was not considered for waveform analysis, failing a similarity check, which is represented by low cross-correlation values on the right graph. 

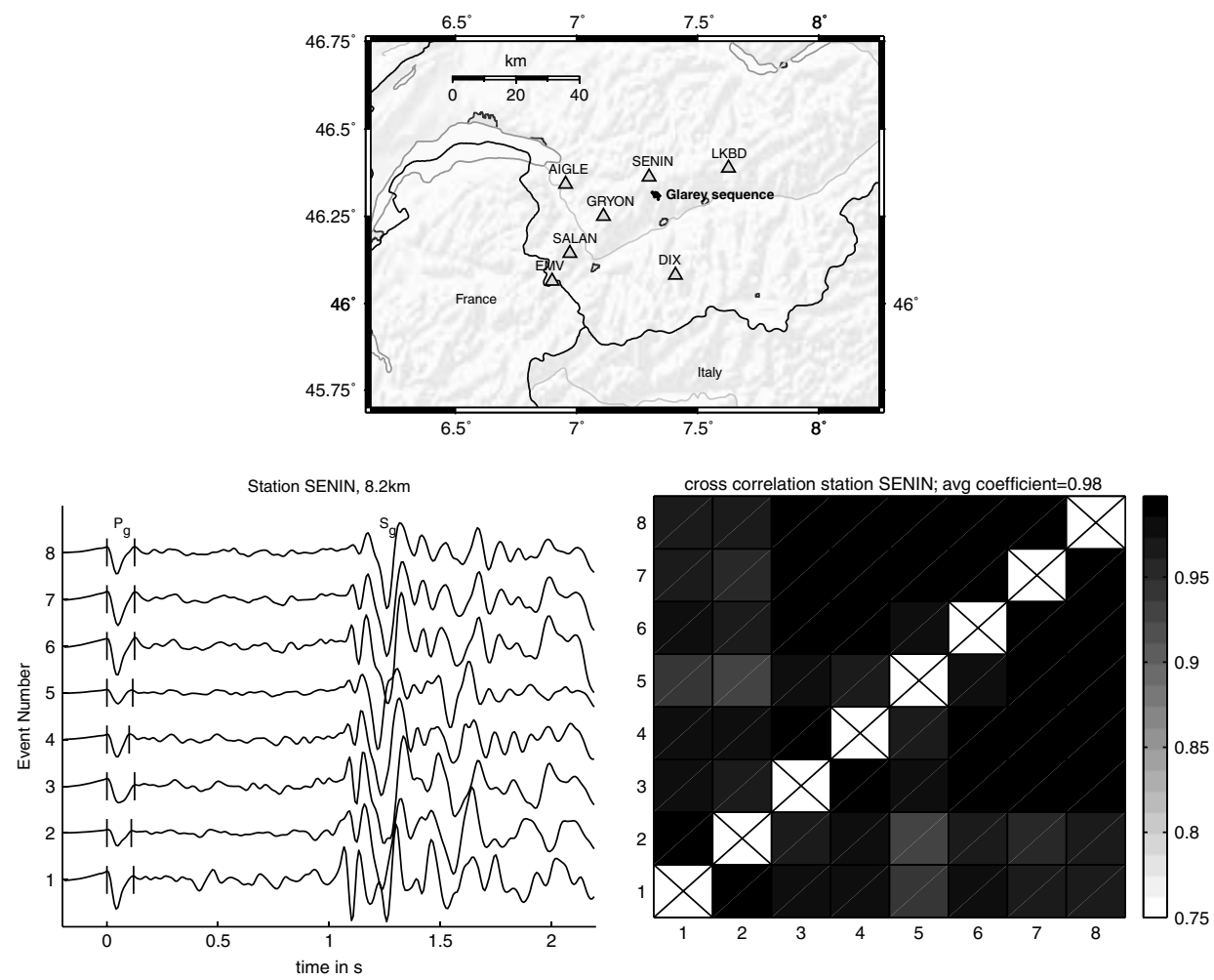

Figure A4. The Glarey sequence consists of 36 events, recorded over 4 months in 2003 in southwest Switzerland. Shown are the first 8 seismograms (band-pass-filtered $2-30 \mathrm{~Hz}$ ) of the sequence at station SENIN in $8.2 \mathrm{~km}$ hypocentral distance and the cross-correlation coefficients of the unfiltered $P_{g}$-wave interval used for analysis.
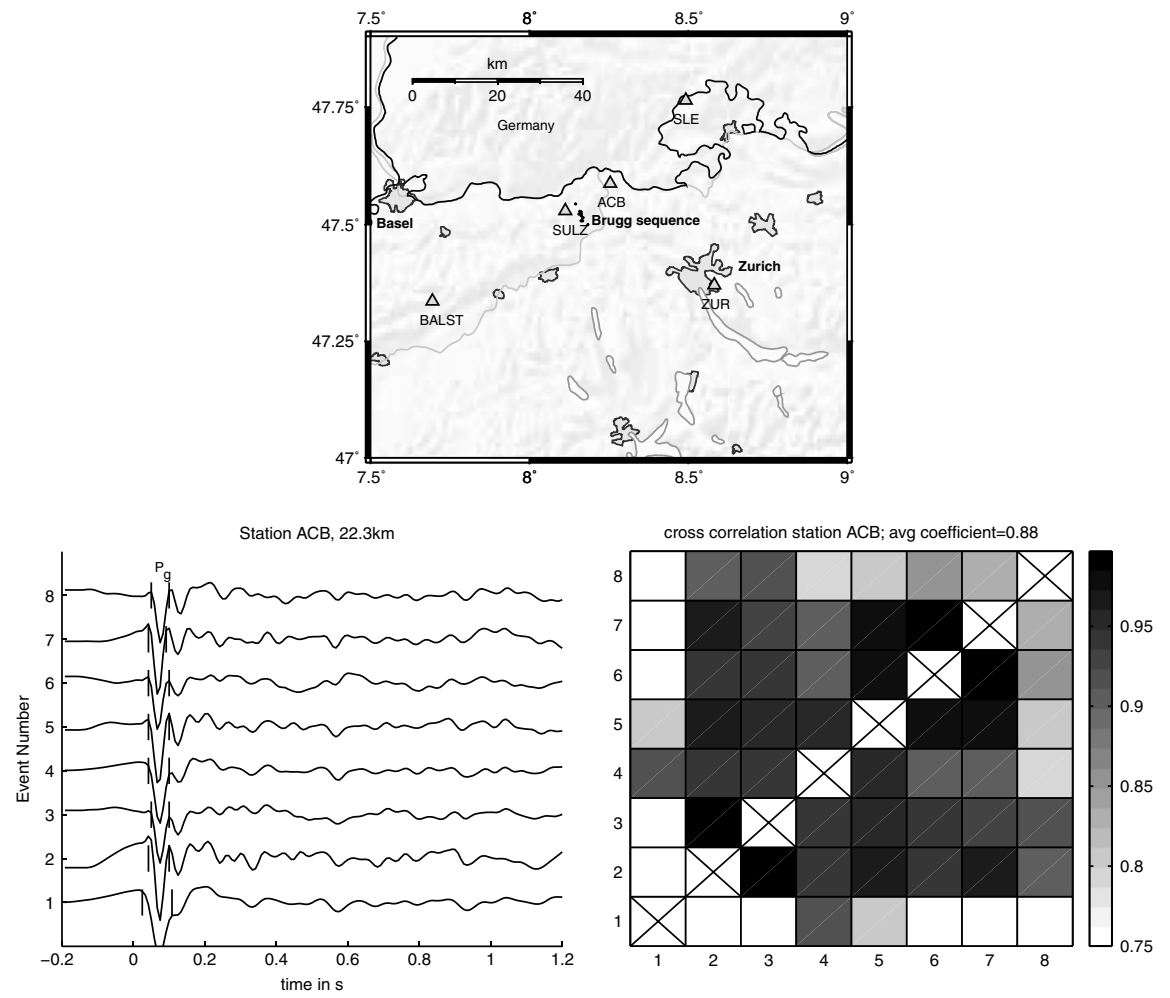

Figure A5. The Brugg sequence consists of 12 events. Seven aftershocks followed the main event in 2004. Another 4 events of similar depth and focal mechanism occurred a year later. Shown are the signals of the first 8 events of the sequence (band-pass-filtered 2 to $30 \mathrm{~Hz}$ ) at station ACB at $22.3 \mathrm{~km}$ hypocentral distance as well as cross-correlation coefficients of the unfiltered $P$ pulses used in the analysis. 

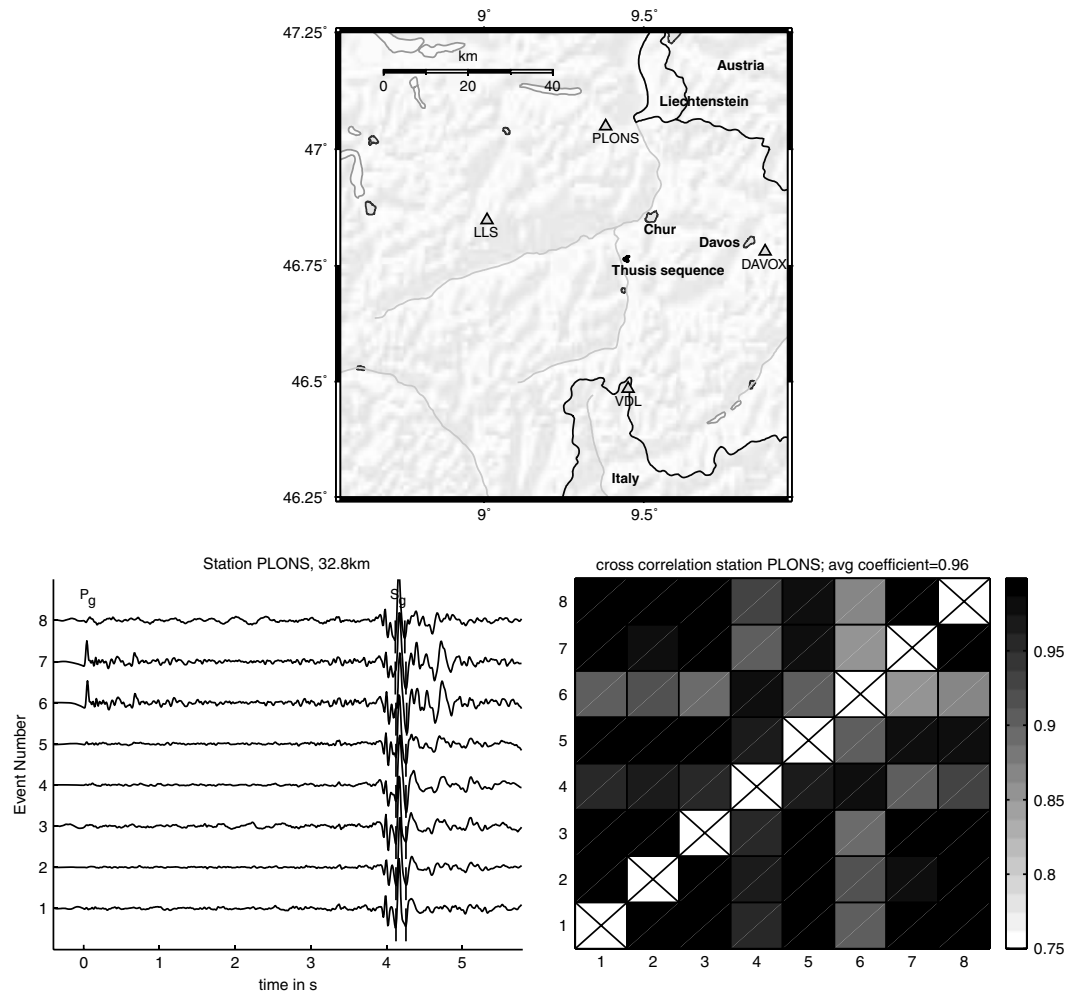

Figure A6. Seismograms recorded at station PLONS at $32.8 \mathrm{~km}$ hypocentral distance (band-pass-filtered 2-30 Hz) and cross-correlation coefficients for the first 8 events of the Thusis sequence. The signals of events 7 and 8 indicate that variations of focal mechanisms exist; however, intervals of the $S$ phase used in the present analysis show high similarity.

occurred within 24 hours after the mainshock; the last event occurred almost 6 months later. A year later the sequence resumed with an event of magnitude $M_{\mathrm{L}} 4.1$ with a similar focal mechanism and the same depth. Three aftershocks that followed within a timespan of three weeks showed similar waveforms of the $S$ phase and identical arrival time differences between $P$ and $S$ wave.

\section{Thusis Sequence}

The Thusis sequence started in 2007 and reached its peak with an $M_{\mathrm{L}} 4.0$ event in February 2008. Activity continued throughout the year 2008 with sporadic events still occurring in 2009. A focal depth of $8 \mathrm{~km}$ is constrained by $S$ - $P$ arrival time differences recorded by a temporary station installed in the immediate epicentral vicinity (Deichmann and Giardini, 2009). The focal mechanism of the main event consists of a near-vertical east-west striking nodal plane and a north-south striking nodal plane dipping rather flatly to the east (Deichmann et al., 2009). For our amplitude study we used signals from 32 similar events out of this sequence. Shown in Figure A6 are the first 8 seismograms band-passfiltered from 2 to $30 \mathrm{~Hz}$ of the sequence and corresponding cross-correlation coefficients for the unfiltered $S$-wave window we use for our analysis. Amplitude ratios of $P$ to $S$ phases (e.g., events 7 and 8) indicate that variations of focal mechanisms exist; however, the $S$-wave intervals considered here show a high similarity, making them suitable for scaling analysis.

Swiss Seismological Service

Institute of Geophysics

ETH Zurich, NO H39.2, Sonneggstrasse 5

CH-8092 Zurich, Switzerland

bethmann@sed.ethz.ch

deichmann@sed.ethz.ch

(F.B., N.D.)

Division of Physical Sciences and Engineering

Building No. 1, Office No. 3114, Level 3

4700 King Abdullah University of Science and Technology

Thuwal 23955-6900, Kingdom of Saudi Arabia

martin.mai@kaust.edu.sa

(P.M.M.)

Manuscript received 26 June 2010 